\title{
Competition between Phasic and Asynchronous Release for Recovered Synaptic Vesicles at Developing Hippocampal Autaptic Synapses
}

\author{
Yo Otsu, ${ }^{1,2}$ Vahid Shahrezaei, ${ }^{4,5}$ Bo Li, ${ }^{1,2}$ Lynn A. Raymond, ${ }^{1,2,3}$ Kerry R. Delaney, ${ }^{5}$ and Timothy H. Murphy ${ }^{1,2,3}$ \\ ${ }^{1}$ Kinsmen Laboratory and Brain Research Centre and Departments of ${ }^{2}$ Psychiatry and ${ }^{3}$ Physiology, University of British Columbia, Vancouver, British \\ Columbia, Canada V6T 1Z3, and Departments of ${ }^{4}$ Physics and ${ }^{5}$ Biological Sciences, Simon Fraser University, Burnaby, British Columbia, Canada V5A 1 S6
}

\begin{abstract}
Developing hippocampal neurons in microisland culture undergo rapid and extensive transmitter release-dependent depression of evoked (phasic) excitatory synaptic activity in response to $1 \mathrm{sec}$ trains of $20 \mathrm{~Hz}$ stimulation. Although evoked phasic release was attenuated by repeated stimuli, asynchronous (miniature like) release continued at a high rate equivalent to $\sim 2.8$ readily releasable pools (RRPs) of quanta/sec. Asynchronous release reflected the recovery and immediate release of quanta because it was resistant to sucroseinduced depletion of the RRP. Asynchronous and phasic release appeared to compete for a common limited supply of release-ready quanta because agents that block asynchronous release, such as EGTA-AM, led to enhanced steady-state phasic release, whereas prolongation of the asynchronous release time course by LiCl delayed recovery of phasic release from depression. Modeling suggested that the resistance of asynchronous release to depression was associated with its ability to out-compete phasic release for recovered quanta attributable to its relatively low release rate (up to $0.04 / \mathrm{msec}$ per vesicle) stimulated by bulk intracellular $\mathrm{Ca}^{2+}$ concentration $\left(\left[\mathrm{Ca}^{2+}\right]_{\mathrm{i}}\right.$ ) that could function over prolonged intervals between successive stimuli. Although phasic release was associated with a considerably higher peak rate of release $\left(0.4 / \mathrm{msec}\right.$ per vesicle), the $\left[\mathrm{Ca}^{2+}\right]_{\mathrm{i}}$ microdomains that trigger it are brief $(1 \mathrm{msec})$, and with asynchronous release present, relatively few quanta can accumulate within the RRP to be available for phasic release. We conclude that despite depression of phasic release during train stimulation, transmission can be maintained at a near-maximal rate by switching to an asynchronous mode that takes advantage of a bulk presynaptic $\left[\mathrm{Ca}^{2+}\right]_{\mathrm{i}}$.
\end{abstract}

Key words: short-term synaptic depression; asynchronous release; phasic release; glutamatergic; readily releasable pool; release probability; hippocampus; autapse

\section{Introduction}

Chemical synapses have the ability to exhibit multiple modes of transmitter release, including high-fidelity action potential (AP)evoked phasic, facilitating and depressing phasic responses elicited by trains of stimulation, and asynchronous forms of transmission such as miniature release (mini) (Atwood and Karunanithi, 2002). Factors contributing to the different modes of release include the number of readily releasable quanta, the release probability of individual vesicles, and the ability to reuse or deliver more quanta from a reserve pool (RP) (Südhof, 2000; Zucker and Regehr, 2002). It is becoming increasingly clear that these different modes of transmission are highly regulated at individual synapses and can have significant functional implications (Atwood and Karunanithi, 2002). Data suggest that even

Received Oct. 1, 2003; revised Nov. 5, 2003; accepted Nov. 5, 2003.

This work was supported by Canadian Institutes of Health Research (CIHR) Grant MT12675 to T.H.M. and Natural Sciences and Engineering Research Council (Canada) Grant RGPIN121698 to V.S. and K.R.D. T.H.M. is a CIHR investigator, and K.R.D. and T.H.M. are Michael Smith Foundation for Health Research senior scholars. We thank Drs. David M. Quastel, Stéphane Dieudonné, Philippe Isope, and Israeli Ran for helpful discussion.

Correspondence should be addressed to Dr. T. H. Murphy, Department of Psychiatry, 4N1-2255 Wesbrook Mall, Vancouver, British Columbia, Canada V6T 1Z3. E-mail: thmurphy@interchange.ubc.ca.

DOI:10.1523/JNEUROSCI.4452-03.2004

Copyright $\odot 2004$ Society for Neuroscience $\quad 0270-6474 / 04 / 240420-14 \$ 15.00 / 0$ asynchronous forms of transmission such as minis are regulated at individual synapses (Murphy et al., 1994) and can contribute to the regulation of synapse properties (McKinney et al., 1999). Here, we apply trains of AP stimuli to hippocampal autaptic synapses to induce brief periods of enhanced mini release to better understand the relationship between phasic and asynchronous modes of release.

Classic experiments indicate that after trains of APs, presynaptic $\mathrm{Ca}^{2+}$ accumulates, leading to a delayed or asynchronous (mini like) release of synaptic vesicles (Barrett and Stevens, 1972). Data indicate that this delayed release is proportional to the bulk (also termed residual) $\left[\mathrm{Ca}^{2+}\right]_{\mathrm{i}}$ (Atluri and Regehr, 1998), in contrast to the brief microdomains of $\left[\mathrm{Ca}^{2+}\right]_{\mathrm{i}}$ that trigger phasic release (Meinrenken et al., 2003). After high-frequency stimulation, phasic release can be depressed to nearly undetectable levels, and an accumulation of asynchronous release is apparent (Cummings et al., 1996; Hagler and Goda, 2001). It is possible that during high-frequency bursts of activity and, in particular, early in development when release probability is high (Bolshakov and Siegelbaum, 1995; Chavis and Westbrook, 2001; Iwasaki and Takahashi, 2001), asynchronous release may actually predominate over phasic release after relatively few repeated stimuli. Here, we set out to examine how asynchronous release 
A

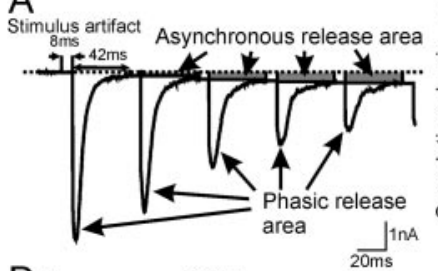

B
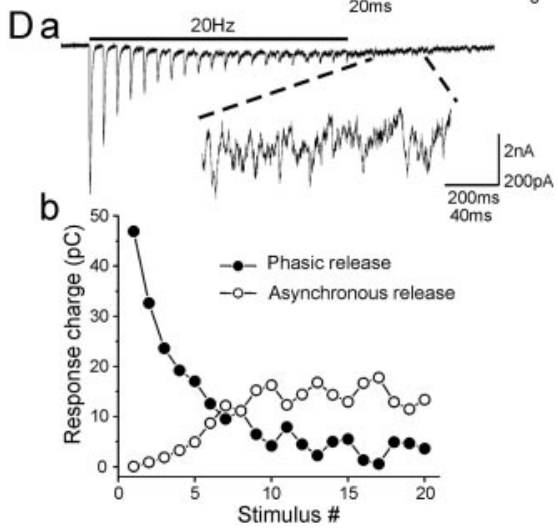

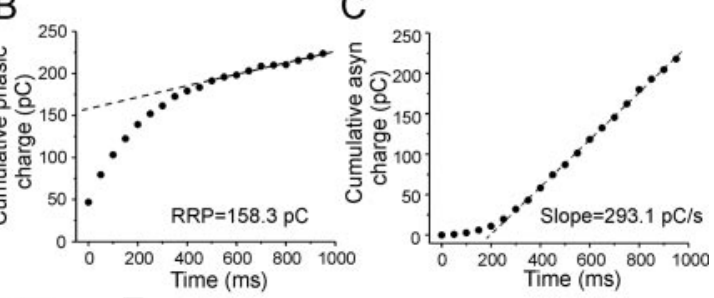

E

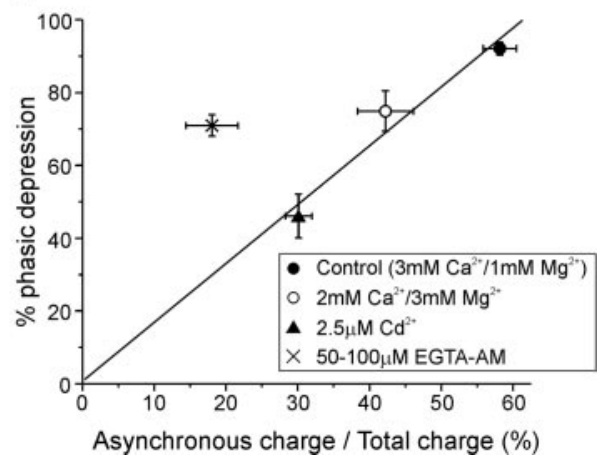

Figure 1. The relationship between phasic and asynchronous release. $A$, Estimation of phasic and asynchronous release components during $20 \mathrm{~Hz}$ stimulation. Baseline before stimulation (1-2 msec), the stimulus artifact, and a part of the capacitive component after the stimulus (induced by a $3 \mathrm{msec}$ depolarization pulse) were removed, resulting in an $8 \mathrm{msec}$ blank period. The phasic release area was estimated by integration for $42 \mathrm{msec}$ under a baseline that was set to the average value of a $1 \mathrm{msec}$ period before each pulse. Asynchronous release area was estimated by integration, as described in Materials and Methods. $B$, Cumulative phasic release components during a $20 \mathrm{~Hz}$ train. Data points ( $50 \mathrm{msec}$ bins) in the range of $600-900$ msec were fitted by linear regression and extrapolated to time 0 to estimate the RRP size with a minimal contribution of refilling. C, Cumulative asynchronous release components during a $20 \mathrm{~Hz}$ train. Data points between 600 and $900 \mathrm{msec}$ were fitted by linear regression to estimate the rate of asynchronous release from the slope. $\mathrm{Da}$, An example of an EPSC trace from a cell stimulated at $20 \mathrm{~Hz}$ for $1 \mathrm{sec}$; stimulus artifacts were removed. Db, Estimates of phasic response $(\mathbf{O})$ and asynchronous release $(\bigcirc)$ from $D a$ are plotted against train number. $E$, Relationship between the extent of phasic release depression and asynchronous release. The extent of phasic response depression (ratio of the mean of the 19th and 20th response to the first phasic response) plotted versus the fraction of total release occurring asynchronously in response to train stimulation measured under the indicated conditions: $3 \mathrm{~mm} \mathrm{Ca}{ }^{2+} / 1 \mathrm{~mm} \mathrm{Mg}{ }^{2+}$ (control condition) $(n=14), 2 \mathrm{~mm} \mathrm{Ca}{ }^{2+} / 3 \mathrm{~mm} \mathrm{Mg}^{2+}(n=7), 2.5 \mu \mathrm{M} \mathrm{Cd}^{2+}(n=4)$, and $>10$ min after bath application of 50-100 $\mu \mathrm{M} \operatorname{EGTA-AM}(n=8)$. Linear regression was fitted with data points, except EGTA-AM data $(r=0.97)$.

can still proceed despite depression of phasic release during repetitive stimulation. One possibility is that asynchronous release may not necessarily be dependent on a store of readily releasable quanta, but rather depend on the process by which quanta are rapidly refilled into the store and subjected to immediate release (Lu and Trussell, 2000). Assuming the depression of evoked release is attributed to the depletion of readily releasable pools (RRPs) of vesicles (Elmqvist and Quastel, 1965; Rosenmund and Stevens, 1996; Dobrunz and Stevens, 1997), the maximum rate of asynchronous release would approximate to the upper limit for the refilling rate of the RRP. Conditions expected to favor a switch to asynchronous at the expense of phasic transmission are slow $\left[\mathrm{Ca}^{2+}\right]_{\mathrm{i}}$ clearance and RRP depletion. The model indicates that asynchronous release can out-compete phasic release for recovered quanta because of its bulk $\left[\mathrm{Ca}^{2+}\right]_{\mathrm{i}}$-stimulated relatively low release rate that functions over prolonged intervals between successive stimuli within a train. The ability of asynchronous release to use recently recovered quanta provides a mechanism to maintain signaling during train stimulation that normally depresses phasic release.

\section{Materials and Methods}

Hippocampal neuronal cultures. Hippocampal neurons were cultured on glial microislands as described previously (Bekkers and Stevens, 1991; Li et al., 2002). Briefly, a $0.15 \%$ agarose solution was spread uniformly on glass coverslips, then a solution of poly-D-lysine $(0.5 \mathrm{mg} / \mathrm{ml})$ and colla- gen $(2 \mathrm{mg} / \mathrm{ml})$ was sprayed on the agarose background. Glial cells derived from rat cortex were then plated on the spots of adhesive surface created by the poly-D-lysine/collagen spray. After the glial microisland feeder layers were confluent, the CA1-CA3 regions of hippocampi were removed from postnatal day 0 to 3 rats and were then enzymatically ( $20 \mathrm{U} / \mathrm{ml}$ papain)/mechanically dissociated and plated onto feeder layers. Cells were grown in a solution based on Neurobasal A medium supplemented with 2.5\% FCS, $2 \% \mathrm{~B} 27,20 \mathrm{~mm}$ glucose, and a $0.2 \%$ penicillinstreptomycin stock. Cultures were used for experiments $4-10 \mathrm{~d}$ after plating.

Electrophysiology. Cultures were superfused continuously with an extracellular recording solution containing (in mM) $134 \mathrm{NaCl}, 2.5 \mathrm{KCl}$, $3 \mathrm{CaCl}_{2}, 1 \mathrm{MgCl}_{2}, 0.34 \mathrm{Na}_{2} \mathrm{HPO}_{4}, 1 \mathrm{NaHCO}_{3}$, 20 glucose, and 10 NaHEPES, pH 7.3-7.4 (osmolarity, $315 \mathrm{mOsm})$. DL-APV $(50-100 \mu \mathrm{M})$, an NMDA receptor antagonist, was included to prevent long-term plasticity. In most experiments, CNQX (0.5-1.5 $\mu \mathrm{M})$, a non-NMDA receptor antagonist, was added to lower peak current amplitude and reduce voltage-clamp errors. The pipette solution contained 112.5 mM K-methansulfonate, $8 \mathrm{~mm} \mathrm{NaCl}, 5 \mathrm{~mm}$ MgATP, 20 mм HEPES, 0.2 mm BAPTA, 20 mm $\mathrm{K}_{2}$-creatine phosphate, and $50 \mathrm{U} / \mathrm{ml}$ creatine phosphokinase, $\mathrm{pH}$ 7.2. Neurons were clamped at $-65 \mathrm{mV}$ with Axopatch 200B. Currents were digitized at $5 \mathrm{kHz}$ and low-pass filtered at $1 \mathrm{kHz}$. The series resistance was compensated $60-70 \%$. Only recordings with series resistance below $20 \mathrm{M} \Omega$ were analyzed. Autaptic EPSCs were evoked by depolarizing the cells from -65 to $0 \mathrm{mV}$ for $3 \mathrm{msec}$. Because synaptic depression can have a long recovery time, paired or single train stimulations $(20 \mathrm{~Hz}$ for $1 \mathrm{sec})$ were repeated at intervals of $\geq 60 \mathrm{sec}$. Holding potentials were not corrected for the liquid junction potential. All experiments were performed at room temperature $\left(22-25^{\circ} \mathrm{C}\right)$. Drugs were prepared as stock solutions at the following concentrations in indicated solvents: EGTA-AM and cyclothiazide (CTZ) at $100 \mathrm{~mm}$ in DMSO and (s)- $\alpha$-methyl-4carboxyphenylglycine (MCPG) at $50 \mathrm{~mm}$ in $0.1 \mathrm{~N} \mathrm{NaOH}$. Final dilutions in the recording solution are stated in the text. When $\mathrm{LiCl}$ was used in the recording solution, $\mathrm{NaCl}$ was replaced with the same concentration (134 $\mathrm{mm}$ ) of LiCl. This solution was applied at 30-60 sec before train stimulation.

Analysis. Phasic and asynchronous components of release during 20 $\mathrm{Hz}$ stimulation were measured as shown in Figure 1. The phasic release component was estimated by integrating the current for $42 \mathrm{msec}$ following each pulse after subtracting a baseline value measured 1-2 msec before each pulse. The asynchronous release component was estimated by subtracting the phasic release from the total integrated current for each $42 \mathrm{msec}$ bin. The baseline holding current measured before the first pulse of a train was subtracted before integration (Fig. $1 A$ ). In the case of paired train experiments, the baseline for the second train was measured after subtraction of the tail component after the first train. To see the relationship between mean and variance of tail currents after train stimulation, the mean amplitude and variance of currents recorded between $42 \mathrm{msec}$ and $1.5 \mathrm{sec}$ after the last pulse of the train (measured over 50 msec bins) were measured. The variance of each bin was corrected by subtracting the baseline variance measured before train stimulation. If the asynchronous tail current is made up of linearly additive elementary components that occur at random intervals, the amplitude of the elementary components is equal to $2 \times$ (variance)/(mean) (Katz and Miledi, 1972). Currents were analyzed off-line using programs written in 
the Interactive Data Language (Research System, Boulder, CO). Spontaneous events miniature EPSC (mEPSC) were detected with an event detection program that is a built-in component of AxoGraph 4.0 (Axon Instruments, Foster City, CA). An event peak was detected with a criteria of a threshold more than three times the SD of the baseline noise. It is possible that the quantal amplitude we estimated from the variance to mean ratio may be an overestimate because of an inability to accurately monitor the effects of variability on mEPSC amplitudes within and between synapses. In this case, estimated quantal amplitudes should be scaled by a factor equal to $1 /\left(1+\mathrm{CV}^{2}\right)$ (Elmqvist and Quastel, 1965 ; Katz and Miledi, 1972). The CV denotes the coefficient of variance of quantal amplitude (SD/mean). The value estimated from mEPSCs in our experiments was $0.76 \pm 0.06(n=5)$, which was similar to that measured by other groups (Bekkers et al., 1990; Forti et al., 1997). In our case, this correction would reduce the estimated quantal amplitude by $\sim 37 \%$. We have not performed the correction, because we are not sure that the CV for mEPSC amplitudes reflects the same distribution of synapses at which asynchronous release occurs.

Computer-controlled solenoid-driven valves were used to rapidly switch between two gravity fed solutions (sucrose and bath solution) contained in a theta tube. The extracellular solution plus $500 \mathrm{~mm}$ sucrose was applied either before or after a train stimulation (for 3-4 sec), as indicated. Although sucrose application provides an accurate measurement of RRP size independent of excitation, it does not have as rapid an onset as synaptic stimulation, preventing us from examining it during the interval from $0-1 \mathrm{sec}$. The size of the sucrose response was measured by binning responses $(200 \mathrm{msec}$ ), and the largest area was used as a RRP size (Stevens and Tsujimoto, 1995).

Train stimulation or hypertonic solutions were applied at intervals $>60 \mathrm{sec}$ to determine the extent of AMPA current and synaptic transmission rundown; the responses decreased by $9.8 \pm 3.9 \%$ in $10 \mathrm{~min}(n=$ 7 ) and $4.7 \pm 6.2 \%$ in $5 \min (n=4)$, respectively. To control for rundown, the test stimuli were normalized to a preceding conditioning train (or sucrose application) given during the preceding $1 \mathrm{~min}$, therefore, the effect of rundown was minimized ( $\sim 1 \%$ over this period).

We estimated asynchronous release rate by measuring the cumulative area of $42 \mathrm{msec}$ bins over $50 \mathrm{msec}$ periods during the interval between pulses. We were not able to measure asynchronous release during the 8 msec of the stimulus period because it was obscured by the stimulus artifact. Similarly, the RRP size was also underestimated, because the decay of the artifact in some cells obscured measurement of phasic release area by a small amount, $5.5 \pm 6.9 \%(2-12 \% ; n=5)$, of phasic area. Therefore, to correct absolute RRP size, we divided it by 0.945 . In the case of asynchronous release, it was corrected for the interval during the stimulus artifact by dividing by 0.84 to reflect periods containing the stimulus artifact.

Statistics were performed using Prism 2.0 (Graph Pad, San Diego, CA). Origin 6.1 was used for curve fitting. Data are displayed as mean \pm SEM.

\section{Results}

\section{Measuring phasic and asynchronous transmission}

We used primary microisland cultures of hippocampal neurons to evaluate the response of CNS synapses to repeated trains of stimulation. Cultures were maintained in vitro for 4-10 d. Based on the kinetics of autaptic synaptic responses and their sensitivity to antagonists, we were able to select excitatory (glutamatergic) neurons and examine their responses to $(1-5 \mathrm{sec})$ repeated $20 \mathrm{~Hz}$ trains of stimulation. Most experiments were conducted in the presence of DL-APV $(50-100 \mu \mathrm{M})$ to block NMDA receptor activation and any associated plasticity. Because autaptic microisland neurons can show very large evoked responses (in excess of $10 \mathrm{nA}$, particularly in the presence of CTZ), it is possible that failure of transmission may occur because of a reduction in input resistance and a shunting active conductance leading to truncated APs. To avoid this, in most experiments (as indicated), we bathed neurons in $0.5-1.5 \mu \mathrm{M}$ of the high-affinity competitive AMPA receptor antagonist CNQX (Honore et al., 1988) to greatly reduce
Table 1. Exponential fittings of the EPSC depression during a $20 \mathrm{~Hz}$ stimulation in the presence of various drugs

\begin{tabular}{|c|c|c|}
\hline & Time constant (msec) & Depression (\%) $^{a}$ \\
\hline Control $(n=10)$ & $234.8 \pm 20.3$ & $91.5 \pm 2.36$ \\
\hline $50 \mu \mathrm{M}$ EGTA-AM $(n=4)$ & $48.2 \pm 8.18$ & $71.2 \pm 6.36$ \\
\hline $2.5 \mu \mathrm{M} \mathrm{Cd}^{2+}(n=4)$ & $541.0 \pm 79.0$ & $46.1 \pm 6.03$ \\
\hline $2 \mathrm{~mm} \mathrm{Ca}^{2+} / 3 \mathrm{~mm} \mathrm{Mg}^{2+}(n=7)$ & $454.7 \pm 68.3$ & $74.9 \pm 5.55$ \\
\hline $100 \mu \mathrm{M} \mathrm{CTZ}(n=4)$ & $125.9 \pm 32.7$ & $98.9 \pm 0.47$ \\
\hline $500 \mu \mathrm{M}$ MCPG $(n=4)$ & $243.1 \pm 47.3$ & $89.0 \pm 1.86$ \\
\hline
\end{tabular}

${ }^{a} 100-$ (average of 19th and 20th phasic/1st phasic area).

the amplitude of the evoked synaptic currents and improve voltage-clamp control. CNQX would also be expected to reduce receptor occupancy during repeated trains of stimulation preventing saturation, allowing us to better observe the effects of repeated quantal release without nonlinear summation. A competitive antagonist should also decrease the likelihood that a receptor (by reducing occupancy) enters a desensitized state in response to the repeated stimuli (see below).

In $3 \mathrm{~mm}$ extracellular $\mathrm{Ca}^{2+} / 1 \mathrm{~mm} \mathrm{Mg}^{2+}$, neurons showed robust depression $(>90 \%)$ of evoked synaptic responses after only $0.5 \mathrm{sec}$ of $20 \mathrm{~Hz}$ stimulation (Fig. $1 D$; Table 1 ). The response to train stimulation was quantified by measuring the area of evoked (phasic) responses. Nonphasic or asynchronous transmission was also estimated as described in Materials and Methods and Figure $1 A$. To examine the relationship between the evoked EPSC and asynchronous quantal release, we monitored both phasic (evoked) and asynchronous release during the trains. To simplify things, we divided each $1 \mathrm{sec}$ evoked stimulation record into 20, $42 \mathrm{msec}$ bins ( $8 \mathrm{msec}$ of each bin contains the stimulus artifact and is used for baseline measurement). In each of these bins, we calculated the total charge influx $(\mathrm{pA} \times$ msec or $\mathrm{pC})$. We then divided this charge influx into phasic and asynchronous components by subtracting the current that was associated with the baseline established just before the stimulus artifact (see Materials and Methods and Fig. 1A). The depression of evoked activity was associated with a high release probability and a depletion of readily releasable quanta, because manipulations that lowered release probability such as $\mathrm{CdCl}_{2}(2.5 \mu \mathrm{M})$ or reduced extracellular $\mathrm{Ca}^{2+}$ greatly reduced the extent of depression (Fig. 1E; Table 1). Furthermore, treatments that reduce AMPA receptor desensitization, such as $100 \mu \mathrm{M}$ CTZ, or block presynaptic metabotropic glutamate receptors, such as $500 \mu \mathrm{M}$ MCPG, also failed to block the depression observed at $20 \mathrm{~Hz}$ (Table 1).

To determine the extent of depression and the rate of recovery from depression for evoked transmitter release, we monitored changes in the RRP size in response to paired $20 \mathrm{~Hz}$ trains that were given at intervals ranging from $150 \mathrm{msec}$ to $60 \mathrm{sec}$. RRP size was defined as the total phasic release that a neuron could sustain in the absence of significant refilling of quanta into the RRP. This was done using the technique of Elmqvist and Quastel (1965), and as applied by others (Schneggenburger et al., 1999; Iwasaki and Takahashi, 2001; Scheuss et al., 2002), in which the cumulative EPSC amplitude was plotted versus time and a linear fit to a steadystate phase was extrapolated to a point on the $y$-axis (reflects RRP size) to subtract the contribution of RRP refilling (Fig. $1 B$ ).

\section{Asynchronous release associated with repeated trains}

After $\sim 10$ stimuli, the amount of asynchronous release exceeded that associated with phasic (evoked) EPSCs (Fig. 1Db). The amount of asynchronous release was positively correlated with the degree of synaptic depression (Fig. 1E). When synaptic 
A

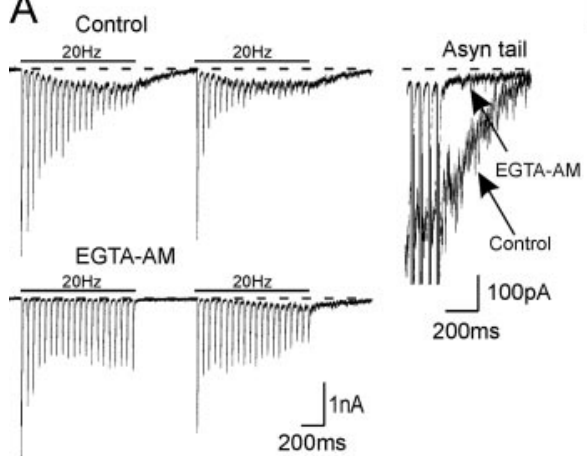

C

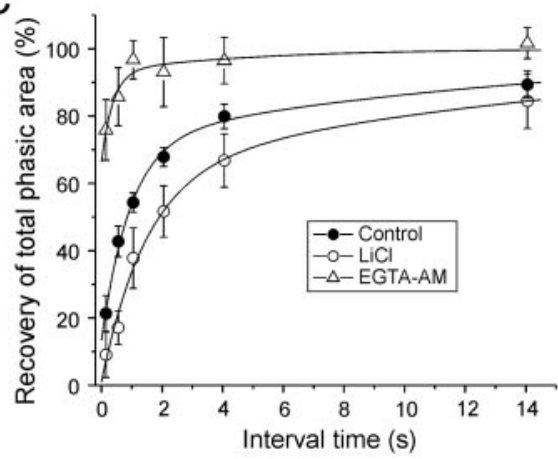

B

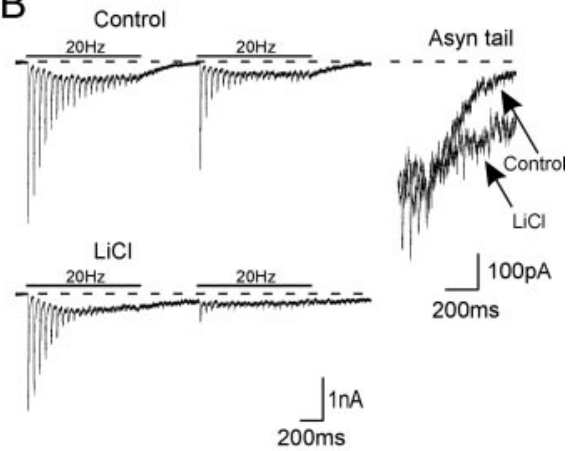

$D$

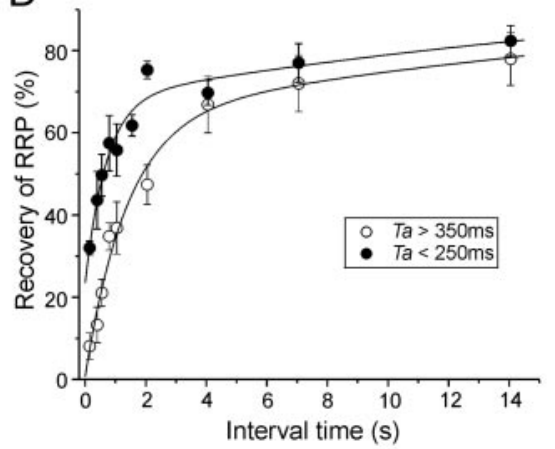

second phasic response could be attributed to a blockade of facilitation mediated by residual $\mathrm{Ca}^{2}$ that normally primes release machinery (Thomson, 2000).

Alternatively, other phenomena such as mobilization of quanta can be dependent on residual $\mathrm{Ca}^{2+}$ (Dittman and Regehr, 1998; Stevens and Wesseling, 1998; Wang and Kaczmarek, 1998). If mobilization were reduced by EGTA-AM, it could explain the apparent facilitated depression of the second response of the train. Interestingly, after EGTA-AM treatment, a high level of steady-state phasic release was observed (Fig. 2A; Table 1). It is conceivable that phasic release was maintained during this period because these quanta were not lost to asynchronous release (see Fig. $7 D$ for modeling of this phenomenon). To further examine this issue in experiments, we gave second trains and found considerably less depression of phasic release during the second train (than under control conditions) (Fig. $2 A, C$ ), consistent with an enhanced recovery of phasic release. Although a higher steady-state level of phasic release was observed in EGTA-AM-treated cells, the total amount of release (phasic plus asynchronous) was depressed by $49.2 \pm 4.2 \%(n=4)$ (compared with untreated controls). These results are consistent with the relative importance of asynchronous release mechanisms and other $\mathrm{Ca}^{2+}$-dependent processes, such as mobilization of quanta (Dittman and Regehr, 1998; Stevens and Wesseling, 1998; Wang and Kaczmarek, 1998), in maintaining synaptic output during high-frequency stimulation.

In contrast to the effect of EGTA-AM, which speeds the initial decay of residual $\mathrm{Ca}^{2+}$ levels, a prolongation of $\left[\mathrm{Ca}^{2+}\right]_{\mathrm{i}} \mathrm{de}-$ cay can be produced if extracellular $\mathrm{Na}^{+}$is replaced by $\mathrm{Li}^{+}$because of reduction in $\mathrm{Ca}^{2+}$ extrusion by the $\mathrm{Na}^{+} / \mathrm{Ca}^{2+}$ ex-

depression was suppressed under conditions such as $\mathrm{CdCl}_{2}$ or reduced extracellular $\mathrm{Ca}^{2+}$, the fraction of total release that occurred asynchronously was also reduced (Fig. $1 E$ ). Previous studies indicate that asynchronous release is dependent on elevated intraterminal residual $\mathrm{Ca}^{2+}$ concentration (Cummings et al., 1996; Atluri and Regehr, 1998). Consistent with these findings, bath application of 50-100 $\mu \mathrm{M}$ EGTA-AM for $10 \mathrm{~min}$ greatly attenuated the delayed asynchronous release, and the cumulative asynchronous release area was suppressed by $82.5 \pm$ $3.4 \%(n=8)$ (Figs. $1 E, 2 A)$. In the presence of EGTA-AM, a small reduction in the first phasic response $(20.5 \pm 5.0 \% ; n=8)$ and a marked acceleration of the rate of depression was observed when the response of the first and second pulses were compared [the ratio of second to first: $82.8 \pm 4.2$ vs $53.6 \pm 3.8 \%$ (before and after EGTA-AM treatment); $n=8$ ]. Presumably, the reduction in the first phasic response was attributable to a reduction in the peak presynaptic $\mathrm{Ca}^{2+}$ concentration (Atluri and Regehr, 1996). In the presence of EGTA-AM, the facilitated depression of the changer (Blaustein and Hodgkin, 1969; Gadsby et al., 1991) Consistent with a dependence of asynchronous release on residual $\mathrm{Ca}^{2+}$, we found that $\mathrm{LiCl}$ greatly prolonged the decay of asynchronous release $\left(\mathrm{T}_{\mathrm{a}}\right)$ (control, $273.1 \pm 91 \mathrm{msec}$; $\mathrm{LiCl}$, $732.5 \pm 267 \mathrm{msec} ; n=5 ; p=0.009$; paired $t$ test) (Fig. $2 B$ ). When we gave a second train in $\mathrm{LiCl}$, the recovery of total phasic release was slower than under control conditions. These recovery data were fitted by biexponential function without needing to add a delay [control: $\mathrm{T}_{\mathrm{f}}=948 \mathrm{msec}(59 \%), \mathrm{T}_{\mathrm{s}}=14.5 \mathrm{sec} ; \mathrm{LiCl}_{\mathrm{f}} \mathrm{T}_{\mathrm{f}}=$ $1.49 \mathrm{sec}(62 \%), \mathrm{T}_{\mathrm{s}}=16.3 \mathrm{sec}$ ) (Fig. $2 B, C$ ). These results are consistent with asynchronously released quanta slowing the apparent recovery of phasic release. A slower rate of recovery (and not necessarily a delay in recovery) is expected if asynchronously and phasicly released quanta compete for a common release and refilling mechanism. Also present in the records from LiCltreated cells was a faster depression (lower steady-state level) of phasic release relative to asynchronous release; the opposite of results obtained with EGTA-AM. Qualitatively, the results with 
$\mathrm{LiCl}$ and EGTA-AM are consistent with asynchronous release slowing phasic release recovery. However, it is possible that these agents may have additional effects making quantitative predictions difficult (Berridge and Irvine, 1989; Dixon and Hokin, 1998). Nonetheless, our model does indicate a large increase in steady-state phasic release using parameters to simulate a block of asynchronous release by EGTA-AM (Fig. 7D).

To further evaluate the relationship between asynchronous release duration and RRP recovery, we compared the time course of RRP recovery in cells with relatively long $\left(\mathrm{T}_{\mathrm{a}},>350 \mathrm{msec}\right.$; $478 \pm 61 \mathrm{msec} ; n=3)$ and short $\left(\mathrm{T}_{\mathrm{a}},<250 \mathrm{msec} ; 155 \pm 24 \mathrm{msec}\right.$; $n=5$ ) periods of asynchronous release (Fig. $2 D$ ). These data indicate two phases of recovery (see below) and were fitted by a biexponential function. We found that prolonged asynchronous release (larger $\mathrm{T}_{\mathrm{a}}$ ) was associated with a relatively slower fast component of phasic release recovery $\left(T_{f}, 1.39 \mathrm{sec}\right.$ vs $\left.693 \mathrm{msec}\right)$. These data are consistent with ongoing asynchronous release slowing the recovery of phasic release from depression.

\section{Variance analysis of asynchronous release}

When stimuli were given at $20 \mathrm{~Hz}$, we noticed that after an initial depression of the evoked (phasic) response, a sustained inward current attributed to asynchronous release of individual quanta was apparent (Fig. 1D). Several lines of evidence (in addition to the effect of EGTA-AM mentioned above) suggest that the sustained current and the additional noise we observed after train stimulation was associated with the asynchronous release of quanta. For example, a subsaturating concentration of CNQX (1 $\mu \mathrm{M})$ reduced both phasic and asynchronous release during train stimulation by similar degrees, indicating that the apparent asynchronous release was not comprised of currents with different antagonist sensitivity (Fig. 3A). Classic studies by Katz and Miledi (1972) indicate the variance to mean ratio can be used to estimate the size of underlying quanta. Using this approach, we have estimated quantal size during the noisy tails that follow train stimulation. The mean amplitude and the variance of the currents in 50 msec bins were measured over $1.5 \mathrm{sec}$ after train stimulation in the presence and in the absence of $1 \mu \mathrm{M}$ CNQX.

In the absence of CNQX, quantal size estimated by a linear fit $\left(R^{2}=0.82 \pm 0.03 ; n=5\right)$ (Fig. $\left.3 B a\right)$ of the relationship between mean and variance was smaller than the measured mEPSC amplitude $(17.0 \pm 3.2$ vs $26.4 \pm 5.9 \mathrm{pA} ; p=0.027 ; n=5$; paired $t$ test) (Fig. $3 C$ ). If quantal size were depressed during the peak of the train, we would expect a hyperbolic relationship in which the variance to mean ratio would be relatively lower for the period of the train with the greatest asynchronous release. To address this, we restricted our linear fitting to the period in which the asynchronous release amplitude is approximately $<100$ pA for noise analysis (linear range). Using this approach, the estimated quantal amplitude $\left(27.6 \pm 6.8 \mathrm{pA} ; R^{2}=0.85 \pm 0.04\right)$ was almost the same as the mEPSC amplitude $(26.4 \pm 5.9 \mathrm{pA})$. This suggests that quantal size was reversibly depressed (without CNQX) during the peak period of asynchronous release. Apparent depression of quantal amplitude could be caused by several factors, including desensitization, saturation of receptors, or limitations of the recording method (see above). Evidence for this included the smaller effect of CNQX on EPSCs recorded in $3 \mathrm{~mm}$ extracellular $\mathrm{Ca}^{2+}$ (EPSC reduced to $17.1 \pm 2.0 \% ; n=5$ ) than those recorded under conditions of lower release probability $\left(1 \mathrm{mM} \mathrm{Ca}^{2+}\right.$; EPSC reduced to $9.4 \pm 1.0 \%$ of control; $n=5 ; p=0.010 ; t$ test) (Fig. $3 A$ ). This result confirmed that the measurement of large responses in the absence of antagonist might lead to errors. Under the conditions we have used, the efficacy of CNQX on the first
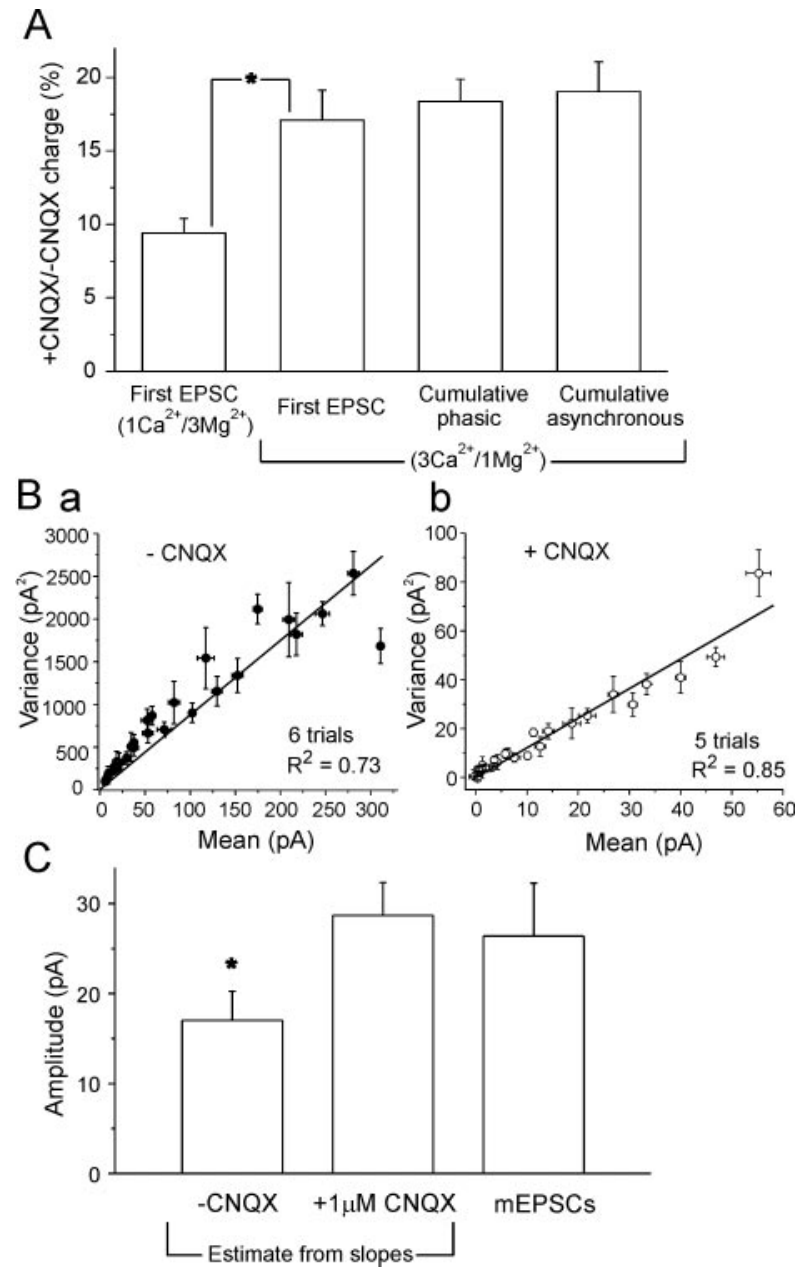

Figure 3. The elementary components of asynchronous release are mEPSCs. $A$, The effect of $1 \mu \mathrm{M}$ CNQX on synaptic responses during $20 \mathrm{~Hz}$ stimulation. Synaptic responses were recorded under $1 \mathrm{~mm} \mathrm{Ca}^{2+} / 3 \mathrm{~mm} \mathrm{Mg}^{2+}(n=5)$ or $3 \mathrm{~mm} \mathrm{Ca}^{2+} / 1 \mathrm{~mm} \mathrm{Mg}^{2+}(n=5)$ (conditions of low and high release probability, respectively). Each bar indicates the fraction of response remaining after $1 \mu \mathrm{M}$ CNQX application (relative to the absence of CNQX). Under conditions of low release probability, the first EPSC was blocked significantly more by CNQX compared with conditions of high release probability ( $p<0.05 ; t$ test). $B$, The relationship between the variance and the mean amplitude of tail currents recorded after the last pulse of the train (measured over 50 msec bins). The variance and the means of the asynchronous currents recorded in the absence $(B a)$ and the presence $(B b)$ of $1 \mu \mathrm{M}$ CNQX are plotted. In the absence and presence of CNQX, linear fitting was used ( $R^{2}=0.76$ and 0.85 , respectively). Regression curve and lines were assumed to pass through zero. C, Comparison of the estimated amplitude (from variance) of elementary components of asynchronous currents with measured mEPSC amplitudes from five cells. The amplitudes were estimated from the slopes in mean-variance relationships in Figure $3 B$ (see Materials and Methods). For solutions that included CNQX, the slope values were divided by a factor of 0.094 to account for $1 \mu \mathrm{M}$ CNQX suppression of the response in $1 \mathrm{~mm}$ $\mathrm{Ca}^{2+} / 3 \mathrm{~mm} \mathrm{Mg}^{2+}$ (see Results). The mean mEPSC amplitude in each cell was obtained from an average of $>95 \mathrm{mEPSC}$ events. Significant differences were observed between the values estimated from asynchronous release under CNQX-free conditions and mEPSC amplitudes ( $p<$ 0.05 ; paired $t$ test)

EPSC of the train should not be affected by the changes in cleft transmitter concentration (associated with $3 \mathrm{mM} \mathrm{Ca}^{2+}$. stimulated release probability), because CNQX dissociates slowly (Honore et al., 1988) and would not be displaced over this time scale.

In the presence of CNQX $(1 \mu \mathrm{M})$, the relationship between mean and variance was linear $\left(R^{2}=0.85 \pm 0.03 ; n=5\right.$ ) (Fig. $3 B b)$. To estimate quantal size, we corrected the slope value with an expected CNQX attenuation factor that was measured by the 
A

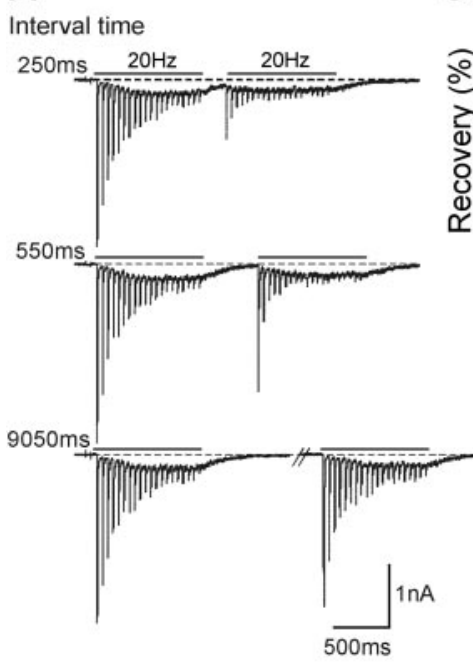

B

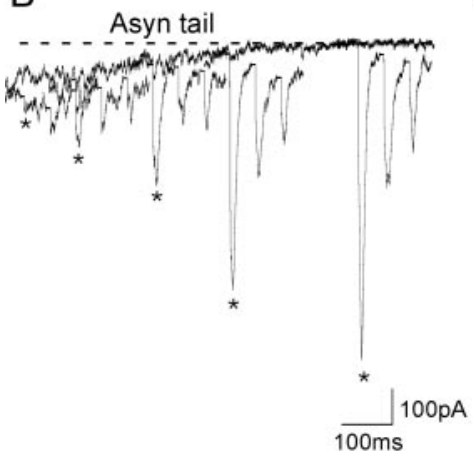

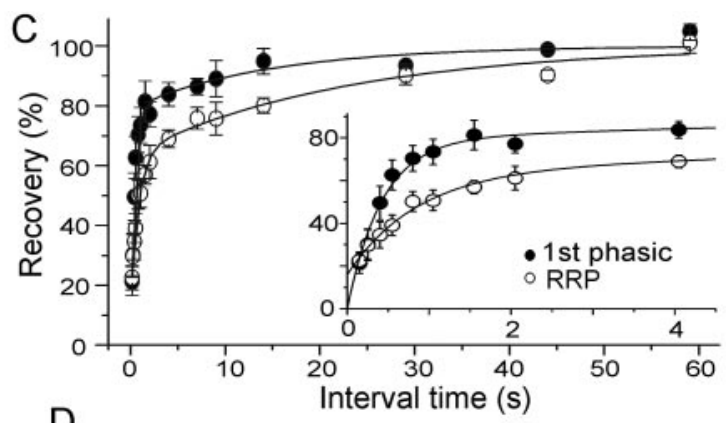

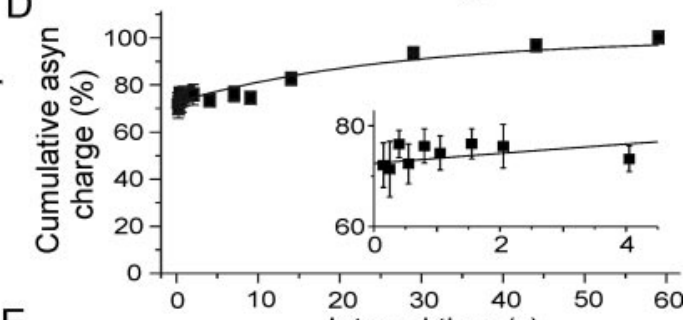

$\mathrm{E}$

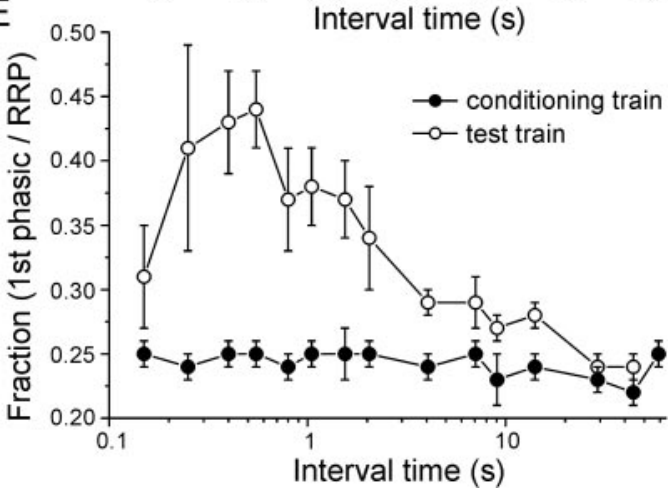

Figure 4. Effect of paired trains on the phasic and asynchronous release. $A$, Conditioning trains ( $20 \mathrm{stimuli}$ at $20 \mathrm{~Hz}$ ) were followed by a test trains ( 20 stimuli at $20 \mathrm{~Hz}$ ) at different intervals as indicated. $B, 0$ verlap between ongoing asynchronous release and phasic release recovery. Current traces from control (no second train) and subsequent test trains (given at varying intervals) are overplotted. An asterisk indicates the first phasic response (subsequent responses within a train occur at 50 msec intervals) in the second train at 150,250,400,550, and 800 msec intervals from the first train (from left side). Stimulus artifacts were removed. C, Time courses of recovery from depression of phasic release (first response of train) and the RRP at different intervals (0.15-60 $\mathrm{sec}$ ). Percentage recovery of first phasic release $=100 \times[\mathrm{I}$ (1st response in test) $-\mathrm{I}$ (20th response in test) $] /[\mathrm{I}$ (1st response in condition) $-\mathrm{I}$ (20th response in test)]. Data were fitted by a biexponential function $\left[f\left(1-e^{-t / T_{f}}\right)+(1-f-\right.$ constant $)$ $\left(1-e^{-t /} \mathrm{T}_{\mathrm{s}}\right)+$ constant] with time constants of $\mathrm{T}_{\mathrm{f}}=425 \mathrm{msec}(f=0.79)$ and $\mathrm{T}_{\mathrm{s}}=14.7 \mathrm{sec}\left(R^{2}=0.99\right)$ in the first phasic release and $\mathrm{T}_{\mathrm{f}}=839 \mathrm{msec}(f=0.48)$ and $\mathrm{T}_{\mathrm{s}}=22.8 \mathrm{sec}\left(R^{2}=0.99\right)$ in the RRP. The inset shows these traces on an expanded timescale. $D$, Time course of recovery from depression of asynchronous release (cumulative area) plotted as a response ratio, test train/conditioning train. Data were fitted by a monoexponential function with time constants of $26.5 \mathrm{sec}\left(R^{2}=0.92\right)$. The inset shows these traces on an expanded timescale. $E$, Transient increase in release probability after conditioning trains. Release probability was estimated as the ratio of the first phasic response to RRP size. When conditioning was given at long intervals, these values were stable, but in test trains, the release probability peaked at approximately the 500 msec interval and decayed over 2.6 $\sec (n=4-10)$.

effect of CNQX on EPSCs under $1 \mathrm{~mm} \mathrm{Ca}{ }^{2+} / 3 \mathrm{~mm} \mathrm{Mg}^{2+}$ (low release probability) or $3 \mathrm{mM} \mathrm{Ca}^{2+} / 1 \mathrm{~mm} \mathrm{Mg}^{2+}$ (high release probability). Using this approach, we found a good correspondence between the actual mEPSC amplitude and the value derived from the asynchronous noise in the presence of CNQX, which is the slope value divided by the blocking factor of 0.094 measured in $1 \mathrm{mM} \mathrm{Ca}^{2+} / 3 \mathrm{mM} \mathrm{Mg}^{2+}$ (Fig. 3C). This suggested that quantal size during the noisy decay period after trains in the presence of CNQX (in contrast to the absence of CNQX) is relatively constant, ruling out desensitization and/or conductance changes as contributing to the depression and recovery kinetics we observed. Although other investigators have been able to count individual quanta during asynchronous release, in our case, because of the high apparent rates of release and the require- ment to use CNQX to reduce peak-evoked current amplitude to a level that can be well clamped, we have not been able to do such an analysis. In summary, variance analysis indicates that the average amplitude of the elementary components of asynchronous release is similar to mEPSCs.

\section{Two phases of recovery from depression} To examine the relationship between phasic release and synaptic depression more closely, we stimulated with paired trains given at varying intervals (Fig. $4 A$ ) and examined recovery during the second train. It is possible that estimates of the recovery time course based on the amplitude of a single phasic response alone may be misleading, because this value would reflect both the available store of readily releasable vesicles and ongoing short-term plasticity (Stevens and Wesseling, 1998). Therefore, to better monitor the behavior of the RRP, we stimulated using paired trains and measured recovery of RPP content. Using this approach, we observed that the recovery process was described by biexponential components $\left[\mathrm{T}_{\mathrm{f}}=839\right.$ $\operatorname{msec}(48 \%) ; \mathrm{T}_{\mathrm{s}}=22.8 \mathrm{sec}$ ] (Fig. $4 C$, open circles). When the recovery time course was estimated from the first phasic area (first pulse of second train), we also observed biexponential phases of recovery, although recovery appeared to be faster than that observed for RRP size $\left[T_{f}=\right.$ $425 \mathrm{msec}(79 \%) ; \mathrm{T}_{\mathrm{s}}=14.7 \mathrm{sec}$ ] (Fig. $4 C$, filled circles). Therefore, an apparently faster recovery rate and a smaller slow component can result if single EPSCs and not RRP content are used to monitor recovery from depression.

It is possible that the effect of asynchronous release may be to produce a delay in recovery rather than a slower-rate phasic release recovery. However, in plots of the recovery time course, we did not observe a significant delay (Fig. 4C). Furthermore, in cells with a relatively prolonged decay of asynchronous release $\left(T_{a}=521 \mathrm{msec}\right)$, we can observe an overlap between phasic release recovery and ongoing asynchronous release (Fig. $4 B$ ).

\section{Minimal depression of asynchronous release during repeated trains of stimulation}

Although phasic release could be markedly depressed with train stimulation, we observed that asynchronous release was relatively less affected being $\sim 70 \%$ of maximal even after relatively short intervals between trains $(150 \mathrm{msec})$ (Fig. $4 D)$. The depressed component of asynchronous release (30\%) recovered with a similar time course $(\mathrm{T}=26.5 \mathrm{sec})$ as the slow component of phasic release recovery (as defined by RRP size). Like phasic release, our model predicts that asynchronous release is dependent on the size of the RRP and, thus, should be suppressed initially by depletion 
of the RRP with hypertonic solution, as we observed (Fig. 5A). However, it is possible that asynchronous release may be able to out-compete phasic release for recovered quanta because of its relatively low release rate that can function over prolonged intervals between successive stimuli within a train. Our results and model indicate qualitatively that this is the case (Figs. $5 A, 7 D$ ), because over a $1 \mathrm{sec}$ period of stimulation at $20 \mathrm{~Hz}$ asynchronous release is less affected by sucrose-induced RRP depletion than phasic release (Fig. 5Ac). In comparing the experimental data to the model, relatively less asynchronous release is observed at early time points than is predicted (compare Figs. 5Ab, 7D). During 1 sec of train stimulation, the model predicts that prior sucrose treatment will reduce cumulative asynchronous release to $85.2 \%$ of control, whereas we observed it reduced to $68.5 \%$ of control. Given previous reports showing that hypertonic sucrose can produce a small reversible (over seconds) reduction in voltage-gated $\mathrm{Ca}^{2+}$ channel activity, it is not surprising that asynchronous release may initially occur at a lower level than expected (Rosenmund and Stevens, 1996). We also used sucrose application to determine whether our estimates of recovery time course based on phasic responses (using an estimation of RRP size as in Fig. $1 B$ ) were comparable with measurements made by others (Fig. $5 B)$. To evaluate the relationship between RRP size (determined by cumulative phasic charge, as in Fig. $1 B$ ) and the sucrose response, we applied sucrose at varying intervals after train stimulation (Fig. 5Ba). The recovery of the RRP based on sucrose responses was best fit as a single exponential process $\left(\mathrm{T}=4.8 \mathrm{sec} ; R^{2}=0.97\right)$ with an extrapolated value at time 0 of $37 \%$ (Fig. $5 \mathrm{Bb}$ ). The apparent depression of sucrosemediated release by stimulation with an AP train provides additional evidence that train stimulation depletes the RRP, leading to depression of synaptic responses. However, when we compared the recovery of the RRP determined from phasic responses with sucrose, the time courses were quite different (Figs. $4 C, 5 B$ ). This difference may be related to $\mathrm{Ca}^{2+}$-dependent factors that are activated during train stimulation but not during hypertonically evoked release, which does not raise $\left[\mathrm{Ca}^{2+}\right]_{\mathrm{i}}$ (Delaney et al., 1991). However, some of the difference in recovery may also be attributable to the fact that the sucrose response evolves slowly and can be contaminated by refilling and, thus, does not allow resolution of fast components of recovery.

Transient elevation in release probability during paired trains In examining responses to repeated trains, we observed that the second train of a pair would exhibit a faster rate of depression for train intervals between $250 \mathrm{msec}$ and $9 \mathrm{sec}$ (Fig. 4A). To further evaluate this, we estimated release probability by dividing the response area of the first evoked stimulus by RRP size (Fig. $4 E$ ). In this way, release probability is expressed as the fraction of total release that occurs with the first stimulus. Using this analysis, we found that release probability $(0.25 \pm 0.01 ; n=10)$ was relatively constant when trains were repeated with long intervals between them. In contrast, if trains were given at shorter intervals $(<10$ $\mathrm{sec}$ ), an elevation in release probability that peaked at the 500 msec interval was observed (Fig. $4 E$ ). A decline in elevated release probability occurred over the next $3 \mathrm{sec}$.

\section{Prolonged trains block asynchronous release}

If vesicles that are released asynchronously come from the same pool as those released phasicly, it should be possible to eventually deplete asynchronous release using longer trains of stimulation. To do this, we gave neurons trains of 100 stimuli spaced $5 \mathrm{sec}$ apart (Fig. 6A). Using this paradigm, we observed suppression of both phasic and asynchronous release after as few as 5-10 trains. Although both forms of release were depressed, phasic release depressed well before asynchronous release (Fig. $6 \mathrm{~B}$ ). After two or more trains of 100 stimuli, $80 \%$ of the total release was through an asynchronous mechanism. This result suggested to us that quanta released asynchronously are ultimately drawn from a depletable (or inactivatable) source and do not necessarily reflect continuous reuse or recycling of quanta from plasma membrane endocytosis. 


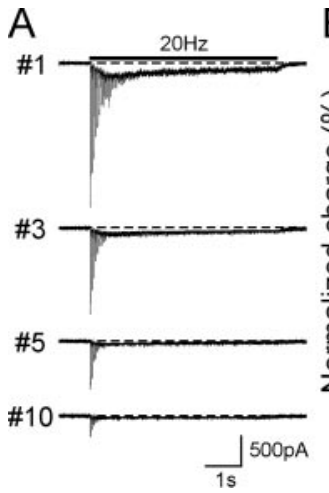

B

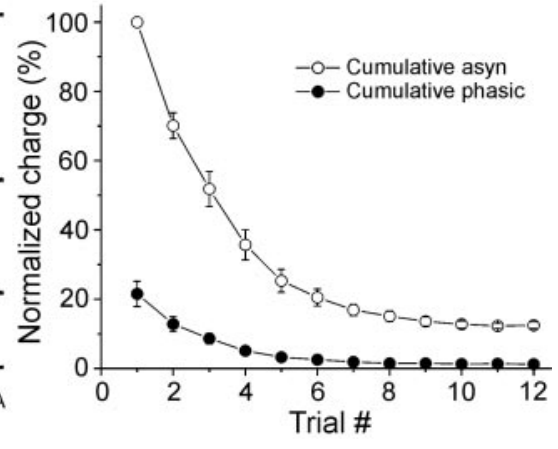

Figure 6. Depression of both phasic and asynchronous release with repeated 100 pulse trains given every $10 \mathrm{sec}$. $A$, Sample records of EPSC trains evoked at $20 \mathrm{~Hz}$ for $5 \mathrm{sec}$ every $10 \mathrm{sec}$ (5 sec intertrain interval). The stimulus sequence numbers (1-10) are indicated. $B$, Changes of cumulative phasic response size $(O)$ and cumulative asynchronous release $(O)$ during repeated trains $(n=9)$. Both areas were normalized to the values of cumulative asynchronous release in first train, respectively.

\section{A common pool model for phasic and asynchronous release}

We hypothesized that the high rate of asynchronous release observed during trains reflects the refilling (or reactivation) of quanta into the RRP and their immediate release given that presynaptic $\left[\mathrm{Ca}^{2+}\right]_{\mathrm{i}}$ is persistently elevated by the train stimulation. In this case, the asynchronous release rate could be an upper limit of the recovery rate. A similar phenomenon was postulated for GABAergic synapses onto avian nucleus magnocellularis neurons (Lu and Trussell, 2000). Moreover, because a prolonged decay of asynchronous release is associated with slower phasic release recovery, it is possible that the two modes of release compete for the same pool of vesicles. To evaluate this further, we produced a simple kinetic model in which we assume that phasic and asynchronous release are derived from the same RRP (Fig. 7). Our experimental data show that the RRP recovers with a slow and a fast time constant (Fig. 4C). We propose two general models that support two time constants in Figure 7A. Model a (Fig. 7Aa) has an RP, and the vesicles dock and undock between the RP and the RRP by fast kinetics (see Appendix). Recycling of used vesicles to the RP occurs through a slow step. Alternatively (Fig. 7Ab), fused vesicles can recycle through the RRP by either a fast or a slow mechanism independent of an RP using Equation 6 in the Appendix (model b). The fast mechanism could be kiss-and-runtype release (Aravanis et al., 2003; Gandhi and Stevens, 2003). In general, experimental evidence suggests that the real situation probably reflects a combination of both models (Zucker and Regehr, 2002) in that there are structurally defined RPs (Richards et al., 2000) and evidence for fast recycling through an RRP (Pyle et al., 2000). Using the $p_{P}$ and $p_{A}$ estimates (measures of phasic and asynchronous release rates, respectively) from fitting the 100 pulse train data, we were able to use either model (Fig. 7Aa or $A b$ ) to explain most aspects of our experimental results. In Figure 7 , we report just the results of the RP model. With regard to the 100 pulse data (Fig. $7 B$ ), initially the probability of asynchronous release is very low (Fig. $7 C$ ), therefore, most of the release is phasic. As the train progresses, the size of the RRP rapidly decreases with each pulse (Fig. 7C), and, accordingly, phasic release is depressed. With continued APs (and accumulation of residual bulk $\left[\mathrm{Ca}^{2+}\right]_{\mathrm{i}}$ ) the probability of asynchronous release grows (Fig. $7 C$ ), and most of the newly recycled vesicles are released asynchronously. The rate of refilling is dependent on the size of the RP and inversely dependent on the RRP size. By Equation 4, the depleted RRP fills faster because $K_{\mathrm{b}} R$ is smaller [(undocking rate $\times(\mathrm{RRP}$ size $)]$. At the end of the train, the RP is partially depleted (Fig. 7C), reducing the rate of recovery and asynchronous release (both depend on RP size; see Appendix). Furthermore, if we consider the alternative model, after a while, the size of $R_{\mathrm{s}}$ grows and then most of the fused vesicles are recovering through the slow process.

The model is able to predict experimental manipulations such as EGTA-AM and sucrose. In experimental data, EGTA-AM blocks asynchronous release by presumably reducing bulk $\left[\mathrm{Ca}^{2+}\right]_{\mathrm{i}}$. In the model, we simulate this by setting the rate of asynchronous release to zero. Using these approaches, both the model and experimental data indicate a higher steady-state level of phasic release in EGTA-AM, presumably through reducing the loss of recovered vesicles to asynchronous release (compare Figs. $2 A, 7 D$; Table 1). Sucrose effects were simulated by starting with a depleted RRP $(r=0)$ and partial depletion of the RP. After dumping the RRP with sucrose, the model and experiments agree qualitatively (Figs. $5 A b, 7 D$ ), demonstrating that asynchronous release (which is presumably related to recovery of quanta) is only modestly affected by sucrose treatment. Furthermore, the model is able to approximate the observed biphasic recovery curve for the RRP (phasic release) (Fig. 7E). Our single-pool model indicated that phasic release must recover from depression with a fast time constant of $460 \mathrm{msec}$ to account for the observed rate of asynchronous release (derived from fitting the recovery of the model data from depression in Fig. $7 E$ ). In contrast, the experimental value of $\mathrm{T}_{\mathrm{f}}$ was $\sim 800 \mathrm{msec}$; there are two explanations for this discrepancy: one is that the experimental data actually does recover faster than $800 \mathrm{msec}$ and that the fitting may be affected by experimental error or the inability to measure recovery at time points shorter than $150 \mathrm{msec}$. Consistent with an effect of experimental error, the recovery time course for phasic release can be fit reasonably well using the faster $\mathrm{T}_{\mathrm{f}}$ of $460 \mathrm{msec}(49 \%)$ derived from the model as a fixed parameter $\left(R^{2}=0.98\right)$. To evaluate whether the inability to resolve recovery at shorter time points affected the fitting, we also fit the experimental data assuming that just after a train the RRP was fully depleted (at time $=0 ; R R P=0$ ) and found a faster time constant of recovery similar to what the model gave $(429 \mathrm{msec})$. The second explanation for the discrepancy is that a simple single-pool model fails to fully account for mechanisms such as calcium-stimulated recovery (Dittman and Regehr, 1998; Stevens and Wesseling, 1998; Wang and Kaczmarek, 1998) and the existence of a separate pool of rapidly recruiting vesicles (Sakaba and Neher, 2001) that, when taken into consideration, could contribute to the high rate of asynchronous release observed in experimental data. Although modest quantitative differences between the model and experiments are apparent, we find that our simulation is robust because it can make predictions regarding the effect of manipulations designed to alter phasic and asynchronous release (sucrose and EGTA, respectively, see above).

Consistent with experimental data, asynchronous release exhibited relatively reduced depression during train stimulation. Depression of phasic release in the second train (when given at short intervals after the first) is expected, because the RRP is nearly depleted by the end of the first 20 pulse train (as in Fig. 4C; see Fig. 7E for model). Given that only a modest depression of the $\mathrm{RP}$ is apparent after 20 stimuli and that asynchronous release can out-compete phasic release for recovering quanta (Fig. $7 C$ ), we only observed partial depression of asynchronous release in the second train in both the model and experimental results (compare Figs. $4 D, 7 E)$. 
The strength of this model is that by using the same set of parameters, we can explain most aspects of our data. One notable change is that for 20 pulse trains, a better fit to experimental data on RRP recovery was obtained with a smaller RP size $(66 \%)$ than that used for 100 pulse trains. We estimated that the RP capacity $\left(S_{\max }\right)$ has a size equal to 8 times the $\operatorname{RRP}\left(R_{\mathrm{r}}\right)$ for 20 pulse trains (Fig. 7C,D) and 12 times $R_{\mathrm{r}}$ for 100 pulse trains. This difference might be related to $\mathrm{Ca}^{2+}$-dependent mobilization of vesicles possibly induced by the longer train (Ryan and Smith, 1995; Dittman and Regehr, 1998; Stevens and Wesseling, 1998; Wang and Kaczmarek, 1998). Although we mention relative sizes for RRP and RPs, it is unclear how these are related to structurally defined docked vesicles or reserve vesicles at a distance from release sites as defined by other groups (Schikorski and Stevens, 1999; Harata et al., 2001). Data from hippocampal neurons indicate a resting pool of quanta that is 20-35 times larger than the RRP (Murthy and Stevens, 1999). Given that the trains we use may lead to vesicle mobilization from both resting and RPs, it is possible that the RP we define has more than one contributor. Our model predicts that the rate of asynchronous release is dependent on the RRP size (Eq. 1 in Appendix), and, therefore, we would expect that conditions associated with an increase in RRP size such as TTX treatment (Murthy et al., 2001) would also lead to more asynchronous release by providing multiple parallel sites at which refilling and release of vesicles could occur.

In evaluating the relationship between the RRP size and the extent of asynchronous release, we have quantified asynchronous release during a train in units of RRP size. The steady-state rate of asynchronous release observed near the end of a train was $2.79 \pm 0.37 \mathrm{RRPs} / \mathrm{sec}[1.8-6.0 \mathrm{RRPs} / \mathrm{sec}$ $(n=10)$, calculated using the approach shown in Fig. $1 C$ ]. At the end of the train, phasic release is nearly completely depressed (RRP empty), and, therefore, the steady-state rate of asynchronous release should not be more than the upper limit of the refilling rate (Stevens and Wesseling, 1999b; Lu and Trussell, 2000). Our results are compatible with these assumptions because the time constant expected for an asynchronous release rate of $2.8 \mathrm{RRPs} / \mathrm{sec}(1 / 2.8=360 \mathrm{msec})$ is faster than the RRP recovery $\left(T_{f}\right)$, based on fitting experimental data or the model: 840 and $460 \mathrm{msec}$, respectively (see Fig. $4 B$ or $7 E$ ). However, the actual recovery rate $\left(\mathrm{T}_{\mathrm{f} \text { (model) }}=250 \mathrm{msec}\right.$ ) used in the model is also higher than these rates. Two factors are major contributors to this difference. The first is that not all quanta recover by the fast mechanism after a single 20 pulse train ( $\sim 50 \%$ of recovery proceeds with a fast component). Second, according to the model, asynchronous release that continues after a train would slow the
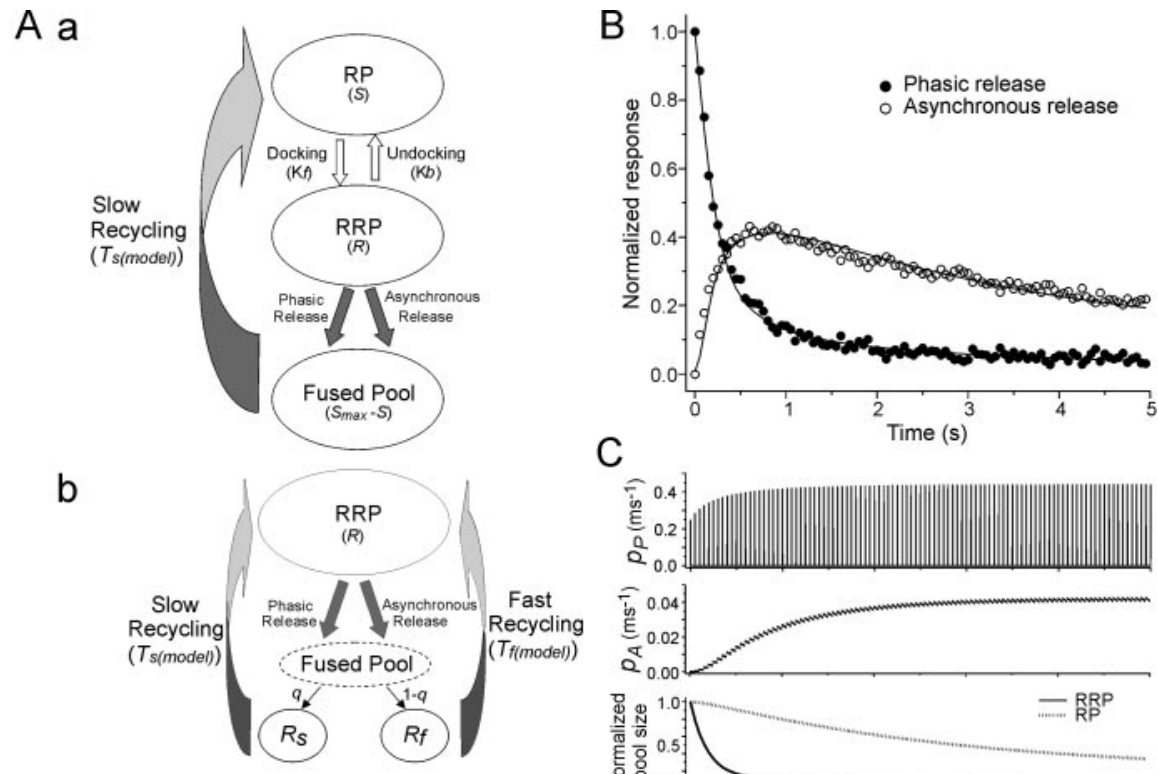

C
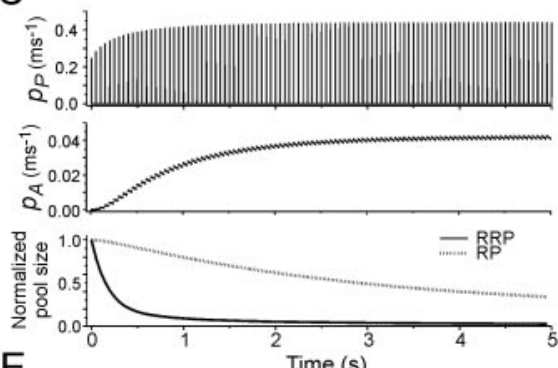

E
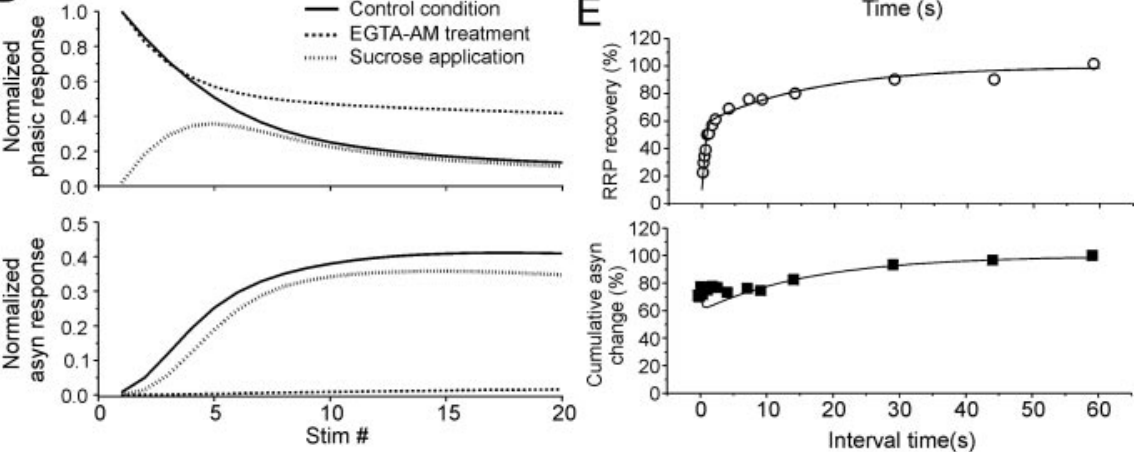

Figure 7. A comparison of modeling and experimental results. $A$, Illustration of the models. $A a, A$ model in which synaptic vesicles are in three pools: RP, RRP, and a fused pool. Vesicles are mobilized from the RP to the RRP with rate constants $k_{\mathrm{f}}$ and $k_{\mathrm{b}}$, released phasicly or asynchronously to the fused pool, and then recover from the fused pool with a rate constant $\mathrm{T}_{\mathrm{s} \text { (model) }}$. $A b, \mathrm{~A}$ model in which synaptic vesicles are in two pools: the RRP and a fused pool. After vesicles are released phasicly or asynchronously, they go to a slow recycling state $\left(R_{\mathrm{s}}\right)$ with probability of $q$ and to a fast recycling state $\left(R_{\mathrm{f}}\right)$ with probability of 1-q. The RRP is refilled by either a slow process $\left(\mathrm{T}_{\mathrm{s} \text { (model) }}\right)$ from $R_{\mathrm{s}}$ or fast process $\left(\mathrm{T}_{\mathrm{f} \text { (model) }}\right)$ from $R_{\mathrm{f}}, B$, Normalized phasic $(O)$ and asynchronous $(O)$ release, experimental average data (9 cells), and model (lines). $C$, Rate of release per vesicle for phasic release ( $p_{p}$ ) and asynchronous release $\left(p_{A}\right)$, in units of $\mathrm{msec}^{-1}$. The rate of phasic release per vesicle is nonzero for just $1 \mathrm{msec}$ at the beginning of each pulse. Normalized RRP size $\left(R(t) / R_{\mathrm{r}}\right)$ and normalized RP size $\left(S(t) / S_{\max }\right)$. D, Predicted phasic and asynchronous responses under (thin dashed line)] using model a (see above).E, Comparison of experimental data and the model for recovery of the $\operatorname{RRP}(\bigcirc)$ and cumulative asynchronous release $(\square)$ with paired train stimulation (experimental data from Fig. $4 C, D$ ). The lines show the asynchronous release. Fitting the simulated phasic release recovery to the equation used in Figure 4 indicated two exponential components: a fast component of $464 \mathrm{msec}(53 \%)$ and a slow component of $17.2 \mathrm{sec}$.

apparent rate of phasic release recovery if both forms of release use the same set of vesicles, machinery, and release sites. Consistent with this proposal, we observed that asynchronous release does not stop immediately after the train and has a $\mathrm{T}_{\mathrm{a}}$ of $\sim 250$ msec [fitting of group data $(n=10)$ indicated time constants of $243 \mathrm{msec}(94 \%)$ and $\left.998 \mathrm{msec}(6 \%) ; R^{2}=1.00\right]$ and, thus, overlaps with the time course of phasic release recovery from depression. Therefore, the actual time constant of recovery (fitted using the model; $\mathrm{T}_{\mathrm{f} \text { (model) }}$; see Appendix) is considerably smaller (faster rate) than that based on the apparent rate of RRP recovery measured in experiments.

We have been to able to illustrate competition between vesicles used for phasic and asynchronous release using a relatively simple model. However, it is possible that additional levels of 
complexity exist, including heterogeneity of pools (Sakaba and Neher, 2001) and calcium-dependent (Heinemann et al., 1994; von Gersdorff and Matthews, 1994; Ales et al., 1999; Sankaranarayanan and Ryan, 2001) endocytosis. Recently, Sun et al. (2002) have shown that the endocytosis rate becomes slower as stimulus frequency or number is higher at calyx synapse. In our study, we have used a constant value for the fast recovery rate $\left(\mathrm{T}_{\mathrm{f}(\text { model })}\right)$ between, during, and after trains and have not incorporated these mechanisms because it would be more difficult to constrain the model without detailed parameters to describe these processes. A relatively simple model may be feasible because we are describing the effect of a constant stimulus frequency. It is conceivable that we would need to incorporate a variable recovery rate if trains of different frequency were used.

\section{Discussion \\ Release-dependent depression of synaptic activity at hippocampal autapses}

We observed robust synaptic depression associated with trains of stimulation. Because synaptic depression at hippocampal autapses can be induced by axonal conduction block, we used relatively low stimulation frequency $(20 \mathrm{~Hz})$ (Brody and Yue, 2000; He et al., 2002). There is evidence for depression by presynaptic metabotropic receptors (Takahashi et al., 1996; Scanziani et al., 1997), desensitization of postsynaptic receptors (Brenowitz and Trussell, 2001; Neher and Sakaba, 2001), and $\mathrm{Ca}^{2+}$ channel inactivation in presynaptic terminals (Forsythe et al., 1998). For the following reasons, we believe the synaptic depression observed with $20 \mathrm{~Hz}$ stimulation is caused by release-dependent depletion of quanta: (1) a reduction in release probability by altering extracellular $\mathrm{Ca}^{2+}$ or using $\mathrm{Cd}^{2+}$ leads to a reduction in synaptic depression; (2) use of CTZ to block AMPA receptor desensitization does not reduce depression; and (3) antagonists of metabotropic glutamate receptors have little effect on the depression time course. Arguing against a role for $\mathrm{Ca}^{2+}$ channel inactivation is the observation that train-induced synaptic depression is associated with a reduction in sucrose-monitored RRP size (Fig. $5 B$ ). Therefore, if depression were attributable to $\mathrm{Ca}^{2+}$ channel inactivation or a change in the $\mathrm{Ca}^{2+}$ sensitivity of release machinery, we would not expect it to affect the size of the RRP determined by $\mathrm{Ca}^{2+}$ independent as sucrose application (Rosenmund and Stevens, 1996). Our data are consistent with release-dependent depression as in hippocampal cultures and slices (Maki et al., 1995; Dobrunz and Stevens, 1997; Hagler and Goda, 2001), neuromuscular junction (Elmqvist and Quastel, 1965; Betz, 1970), and the calyx synapse (Wu and Borst, 1999).

\section{Biphasic recovery of evoked release from depression}

At the neuromuscular junction, the time course of recovery from synaptic depression is dependent on the duration of train stimulation, with slower recovery occurring with longer trains (Elmqvist and Quastel, 1965; Betz, 1970). The different components were thought to reflect the recovery of an RRP of quanta and an RP (Heuser and Reese, 1973; Wu and Betz, 1998). Similarly, two kinetic components of recovery have been reported by several CNS studies (von Gersdorff and Matthews, 1997; Dittman and Regehr, 1998; Stevens and Wesseling, 1999b; Wu and Borst, 1999; Sakaba and Neher, 2001). Stevens and Wessling (1999b) proposed that the slow component reflects an inhibitory or repair process and not necessarily the refilling of an RP. Data argue against inhibitory events because multiquantal release is apparent at individual release sites (Abenavoli et al., 2002). RRP refilling rates may also vary between release sites within a single syn- apse (Sakaba and Neher, 2001). Other models propose that the faster component represents the reuse of depleted RRP vesicles (Pyle et al., 2000; Sara et al., 2002), whereas the slow component is attributed to repopulation of the RRP from the RP. Our data suggest biexponential phases of recovery from depression, although, again, it is unclear whether the slow phase reflects an RP or a slower step in the reuse of spent quanta.

\section{Transient increase in release probability after train stimulation}

Our data show that the release probability in the test trains was higher than in conditioning trains (Fig. $4 E$ ), indicating that despite a smaller RRP size, the release probability was higher. These data are consistent with other studies that RRP size is not the only determinant of the release probability (Stevens and Wesseling, 1999a; Hanse and Gustafsson, 2001; Iwasaki and Takahashi, 2001; Xu-Friedman et al., 2001; Millar et al., 2002). Dobrunz (2002) reported that at hippocampal synapses during trains the release probability per vesicle increases, whereas the RRP size decreases. Therefore, although a correlation between RRP size and release probability is apparent, when a population of resting synapses are studied (Dobrunz and Stevens, 1997; Murthy et al., 2001), the relationship does not necessarily hold for trains.

Comparison of phasic and asynchronous release mechanisms Although phasic release can be markedly depressed by repeated synaptic stimuli, asynchronous release is relatively resistant. This difference likely results because asynchronous release reflects the immediate release of newly refilled quanta into the RRP and not necessarily the store of releasable quanta after RRP depletion. We have extended the study by Lu and Trussell (2000) to excitatory transmission in hippocampal neurons and have used a combination of sucrose and AP-evoked release to assess the effect of RRP content on asynchronous release. The differential sensitivity of phasic and asynchronous release to EGTA-AM is consistent with proposals that asynchronous release is triggered by a relatively lower $\left[\mathrm{Ca}^{2+}\right]_{\mathrm{i}}$ (than phasic release) that can be maintained during the interval between repeated APs. The preferential role of asynchronous release during long trains of stimuli (as opposed to phasic release) is likely the result of sustained occupancy of the asynchronous release $\mathrm{Ca}^{2+}$ sensor during the prolonged trains and not necessarily a process by which phasic release is inhibited. Our simulation data support this proposal because we were able to shift to a predominantly asynchronous release mechanism by gradually raising the probability of asynchronous release without having to add mechanisms that inhibit phasic release (lower $p_{\mathrm{A}}$; see Appendix). Phasic release, which requires high $\left[\mathrm{Ca}^{2+}\right]_{\mathrm{i}}$ associated with microdomains, would only be expected to occur briefly $(<1 \mathrm{msec}$ ) in association with each AP (Meinrenken et al., 2003). Therefore, if train stimulation increases the rate of asynchronous release, relatively few recovered RRP vesicles would be able to accumulate for phasic release during the brief time between successive stimuli in a train, leading to an apparent inhibition of phasic release (Fig. 7, model). During train stimulation, phasic release can be depressed, and a high rate of asynchronous release is observed that presumably is a measure of the maximal recovery rate of the terminal. Interestingly, this rate of asynchronous release $(\sim 2.8 \mathrm{RRPs} / \mathrm{sec})$ is far greater than that expected from the recovery kinetics of phasic release $(<0.5$ RRPs recovered in $800 \mathrm{msec}$ ) (Fig. $4 \mathrm{C}$ ). These results are consistent with a considerable slowing of phasic release recovery because of quanta lost through ongoing asynchronous release. However, it is also possible that a simple single-pool model fails to fully account for 
mechanisms such as calcium-stimulated recovery (Dittman and Regehr, 1998; Stevens and Wesseling, 1998; Wang and Kaczmarek, 1998) and the existence of a separate pool of rapidly recruiting vesicles that could selectively undergo asynchronous release (Sakaba and Neher, 2001) (see Results).

To further evaluate mechanistic distinctions between asynchronous and phasic release, we modeled the rates of phasic and asynchronous release and agents that perturb them. Because residual $\mathrm{Ca}^{2+}$ drives the fast component of recovery from depression (Dittman and Regehr, 1998; Stevens and Wesseling, 1998; Wang and Kaczmarek, 1998) as well as asynchronous release, the fast time constant that we estimate for phasic release recovery reflects both refilling of quanta and their loss because of asynchronous release. Assuming phasic and asynchronous release use a similar RRP and release machinery, a high rate of asynchronous release would slow recovery of phasic release because relatively few quanta would be able to accumulate within the RRP. Experimental manipulations support this proposal. Agents such as $\mathrm{LiCl}$ that prolong the time course of asynchronous release slow phasic recovery, whereas EGTA-AM that suppresses asynchronous release results in more rapid recovery of phasic release (Fig. 2C). In contrast, if asynchronous release and phasic release were occurring at different synapses or involving functionally distinct RRPs within a synapse, we would not expect a reciprocal relationship between phasic and asynchronous release.

The time courses of phasic release recovery and asynchronous release overlap, resulting in an apparent competition between mechanisms. To assess whether the recovery rate of phasic release is affected by asynchronous release, we have relied on experimental manipulations that either increase or decrease asynchronous release. Because we have manipulated asynchronous release largely by altering intracellular calcium dynamics, it is conceivable that there may be effects of calcium on the rapid recovery process itself (Stevens and Wesseling, 1998; Wang and Kaczmarek, 1998). However, previous work indicates that $\left[\mathrm{Ca}^{2+}\right]_{\mathrm{i}}$ speeds recovery by approximately twofold (Wesseling and Lo, 2002), in contrast to the effect of $\mathrm{Ca}^{2+}$-stimulated asynchronous release, which slows recovery of phasic release. Furthermore, this effect reaches a ceiling during short trains, suggesting that may already be occurring at a maximal rate before modulation by $\mathrm{LiCl}$ or other agents.

In our study, we cannot determine whether the recovery of phasic release reflects rapid vesicle reuse or movement from an RP. Ultimately, both asynchronous and phasic release depend on a depletable supply of vesicles because both mechanisms can be blocked with a prolonged stimulation. Our models suggest that this could be caused by depletion of vesicles within the RP (model a) or accumulation of vesicles within a slow recovery step of a single RRP (model b). Interestingly, when longer trains are given an even larger role, asynchronous release was evident. Therefore, if developing synapses are continuously stimulated, it is likely that they will switch to an asynchronous release mechanism. Perhaps, under these conditions, the need to preserve excitatory drive outweighs a requirement for temporal fidelity.

\section{Appendix}

\section{A model of phasic and asynchronous release}

Here, we propose a general model of phasic and asynchronous release that is dependent on a common RRP. If we call the size of the RRP at a given time $[R(t)]$, then the rate of phasic release
$[P(t)]$ and the rate of asynchronous release $[A(t)]$ would be proportional to $R(t)$ :

$$
\begin{aligned}
& P(t)=p_{\mathrm{P}}(t) R(t) \\
& A(t)=p_{\mathrm{A}}(\mathrm{t}) R(t) .
\end{aligned}
$$

The proportionality constants $p_{P}(t)$ and $p_{A}(t)$ are the rates of phasic and asynchronous release per vesicle, respectively. Based on previous work and differential sensitivity to relatively slow $\mathrm{Ca}^{2+}$ buffer such as EGTA-AM, $p_{P}$ is microdomain $\left[\mathrm{Ca}^{2+}\right]_{\mathrm{i}}$ dependent (Meinrenken et al., 2003), and $p_{A}$ is bulk $\left[\mathrm{Ca}^{2+}\right]_{\mathrm{i}}$ dependent (Atluri and Regehr, 1998). Therefore, during a $20 \mathrm{~Hz}$ train, $p_{P}$ reaches a finite value for a short time $(\sim 1 \mathrm{msec})$ at the beginning of each spike and is zero between the spikes (Fig. 7C). Consistent with experimental data, $p_{P}$ can also exhibit enhancement after each spike. In contrast, $p_{A}$ is zero at the beginning of the train, and it gradually grows after each spike and reaches a plateau (Fig. 7C). The final level of $p_{A}$ is much lower than $p_{P}$ but it acts over a longer time scale (50 msec vs $1 \mathrm{msec}$ in the case of each 50 msec bin of a $20 \mathrm{~Hz}$ train), allowing asynchronous release to potentially exceed phasic release (Fig. $7 B$ ) during extended periods of elevated bulk $\left[\mathrm{Ca}^{2+}\right]_{\mathrm{i}}\left(\right.$ high $\left.p_{A}\right)$. For estimating the $p_{P}$ and $p_{A}$, we used an estimate of residual $\mathrm{Ca}^{2+}$. During each pulse, a certain amount of $\mathrm{Ca}^{2+}$ comes in to the nerve terminal, which results in an increment in residual bulk $\left[\mathrm{Ca}^{2+}\right]_{\mathrm{i}}$. Therefore, the $\left[\mathrm{Ca}^{2+}\right]_{\mathrm{i}}$ would be proportional to the number of pulses in the train in the absence of $\mathrm{Ca}^{2+}$ sequestration. The $\left[\mathrm{Ca}^{2+}\right]_{\mathrm{i}}$ dynamics are described by the following equation:

$$
\frac{d\left[\mathrm{Ca}^{2+}\right]_{i}}{d t}=\left(\left[\mathrm{Ca}^{2+}\right]_{\mathrm{i}}-\left[\mathrm{Ca}^{2+}\right]_{0}\right) / T_{\mathrm{Ca}}+\sum_{\mathrm{n}} \delta\left(t-t_{\mathrm{n}}\right) .
$$

Where $\left[\mathrm{Ca}^{2+}\right]_{0}$ is at resting levels, we assume it is small compared with that associated with stimulation and set it to zero. $T_{\mathrm{Ca}}$ is the $\mathrm{Ca}^{2+}$ sequestration time constant, and $t_{\mathrm{n}}$ is the time for the $n$th pulse. $\delta$ is a Dirac delta function that is equal to one when its argument is equal zero and it is zero otherwise. The last term describes the summation of $\mathrm{Ca}^{2+}$ and produces a unit increment to the residual $\mathrm{Ca}^{2+}$ level with each pulse. For our model, $\left[\mathrm{Ca}^{2+}\right]_{\mathrm{i}}$ is measured in units of single-pulse residual $\mathrm{Ca}^{2+}$ increment, $\Delta\left[\mathrm{Ca}^{2+}\right]_{\mathrm{i}}$ (bulk concentration). Because we do not have experimental estimates of the residual $\Delta\left[\mathrm{Ca}^{2+}\right]_{\mathrm{i}}$ increment, we have not given it a concentration value. The actual value of the $\Delta\left[\mathrm{Ca}^{2+}\right]_{\mathrm{i}}$ increment is not critical because Equation 3 uses the ratio of concentrations (so it cancels out in the calculation of $p_{A}$ and $p_{P}$ ). $T_{\mathrm{Ca}}$ is related to the decay of asynchronous release time constant $\left(T_{\mathrm{a}}\right)$ times the $\mathrm{Ca}^{2+}$ cooperativity of asynchronous release $\left(N_{\mathrm{A}}\right.$; defined below).

We assume the rates of phasic and asynchronous release have the following forms:

$$
\begin{gathered}
P_{\mathrm{P}}=P_{\mathrm{P}}^{0}+\left(P_{\mathrm{P}}^{\max }-P_{\mathrm{P}}^{0}\right)\left(\frac{\left[\mathrm{Ca}^{2+}\right]_{\mathrm{i}}}{\left[\mathrm{Ca}^{2+}\right]_{\mathrm{i}}+K_{\mathrm{P}}}\right)^{\mathrm{N}_{\mathrm{P}}} \\
P_{\mathrm{A}}=P_{\mathrm{A}}^{\max }\left(\frac{\left[\mathrm{Ca}^{2+}\right]_{\mathrm{i}}}{\left[\mathrm{Ca}^{2+}\right]_{\mathrm{i}}+K_{\mathrm{A}}}\right)^{\mathrm{N}_{\mathrm{A}}}
\end{gathered}
$$

is the initial rate of phasic release, which is presumably $\mathrm{Ca}^{2+}$ microdomain dependent. $P_{\mathrm{P}}^{\max }$ is the maximum rate of phasic release after residual $\mathrm{Ca}^{2+}$-dependent enhancement. The initial rate of asynchronous release is zero, and after elevation of residual $\mathrm{Ca}^{2+}$, it can reach to $P_{\mathrm{A}}^{\max }$. Because the $\left[\mathrm{Ca}^{2+}\right]_{\mathrm{i}}$ remains finite, the $p_{A}$ and $p_{P}$ will never reach their maximum values $P_{A}^{\max }$ and 
$P_{\mathrm{P}}^{\max } . K_{\mathrm{P}}$ and $K_{\mathrm{A}}$ are the affinities of the sites for phasic enhancement and asynchronous release, respectively, and $N_{\mathrm{P}}$ and $N_{\mathrm{A}}$ are corresponding $\mathrm{Ca}^{2+}$ cooperativities.

Our experimental data show that the RRP recovers with both a slow and a fast time constant (Fig. 4C). We propose two general types of models that support these two time constants in Figure $7 A$. Model a has an RP [with size $S(t)$ at time $t$, we denote this pool as $S$ for the store of the vesicles] and an RRP [with size $R(t)$ at time $t]$. The vesicles dock and undock between the RP and the RRP by fast kinetics. Vesicles fuse from the RRP and go to the fused pool $(F)$. Recycling of used vesicles from the fused pool to the RP is through a slow step. It is not necessary to explicitly model the fused pool, because the total number of vesicles is a constant $\left(S_{\max }\right)$ equal to the sum of the RP, RRP, and $F$ :

$$
S+R+F=S_{\max }
$$

If $R \ll S_{\max }, S$, then:

$$
F \approx S_{\max }-S
$$

The kinetics of this model are described by the following equations for $R$ and $S$ :

$$
\begin{gathered}
\frac{d R}{d t}=-P-A+k_{\mathrm{f}} S-k_{\mathrm{b}} R \\
\frac{d S}{d t}=-k_{\mathrm{f}} S+k_{\mathrm{b}} R+\frac{\left(S_{\max }-S\right)}{T_{\mathrm{s} \text { (model })}} .
\end{gathered}
$$

$T_{\mathrm{s} \text { (model) }}(20 \mathrm{sec})$ is the rate of recovery of the RP. $k_{\mathrm{f}}$ and $k_{\mathrm{b}}$ are the rates of docking and undocking, respectively, and are related to the resting size of RRP, $\left(R_{r}\right)$, and fast recovery time constants $\left(T_{\mathrm{f} \text { (model) }}=250 \mathrm{msec}\right.$; see below). By looking at the zero release condition, one can find the following relationships:

$$
\begin{gathered}
T_{\mathrm{f}(\text { model })}=\frac{1}{k_{\mathrm{f}}+k_{\mathrm{b}}} \\
R_{\mathrm{r}}=S_{\max } \frac{k_{\mathrm{f}}}{k_{\mathrm{b}}}
\end{gathered}
$$

The RP-dependent model (Fig. 7Aa) is similar to the classic multipool models (Birks and Maclntosh, 1961; Elmqvist and Quastel, 1965; Liu and Tsien, 1995; Wu and Betz, 1998; Zucker and Regehr, 2002). We use the term RP loosely, because recent data suggest that there may be three pools: the RRP, the RP (these are included in recycling pool), and a nonrecycling pool (resting pool) (Südhof, 2000). It is possible that the $S$ may reflect both the reserve and resting pools of synaptic vesicles, given that the developing neurons we use are undergoing robust release, leading to depletion of the RRP with $1 \mathrm{sec}$ of $20 \mathrm{~Hz}$ stimulation. To refill this RRP, multiple sources may be required. One potential complication of using a multipool model is that the size of the RRP in relation to the RP is determined by the ratio of docking $\left(k_{\mathrm{f}}\right)$ and undocking $\left(k_{\mathrm{b}}\right)$ rate constants (Eq. 5 ; see below):

Therefore, for $R_{\mathrm{r}}$ to be smaller than $S_{\max }, k_{\mathrm{b}}>k_{\mathrm{f}}$. Given values of $k_{\mathrm{f}}$ in the range of $0.3 / \mathrm{sec}$, this implies a considerably faster undocking rate $\left(k_{\mathrm{b}}\right)$ of $3.7 / \mathrm{sec}$ than is observed experimentally using FM1-43 fluorescence (Murthy and Stevens, 1999). We should stress that we are using the classical model to largely describe the slow component of recovery from depression and that the initial rates of phasic release recovery would be dominated by $k_{\mathrm{f}}$ given that $S \gg R$ when the pool is depleted. However, it is also possible that the undocking rates measured experimentally with FM dyes are not necessarily applicable to all modes of release, in particular, a reuse model (Pyle et al., 2000) or endocytosis involving cisternae (Richards et al., 2000). Furthermore, until more dynamic vesicle labeling experiments can be performed, there is still some uncertainty about the relative sizes and nature of different CNS neuron synaptic vesicle pools (Südhof, 2000).

An alternative model (Fig. 7Ab) that also uses Equation 1 to describe phasic and asynchronous release as a function of time has an RRP that fused vesicles can recycle through by either a fast or a slow mechanism, using the following equations:

$$
\begin{gathered}
\frac{d R}{d t}=-P-A+\frac{R_{\mathrm{s}}}{T_{s(\text { model })}}+\frac{R_{f}}{T_{f(\text { model })}} \\
\frac{d R_{s}}{d t}=q(P+A)-\frac{R_{s}}{T_{s(\text { model })}} \\
\frac{d R_{f}}{d t}=(1-q)(P+A)-\frac{R_{f}}{T_{f(\text { model })}} .
\end{gathered}
$$

\begin{tabular}{|c|c|c|}
\hline Name & Definition & Value \\
\hline$T_{\mathrm{Ca}}$ & The $\mathrm{Ca}^{2+}$ sequestration time constant & $1 \mathrm{sec}$ \\
\hline$P_{\mathrm{p}}^{0}$ & The initial phasic release rate/vesicle & $0.25 \mathrm{msec}^{-1}$ \\
\hline$P_{\mathrm{P}}^{\max }$ & The maximum phasic release rate/vesicle & $0.5 \mathrm{msec}^{-1}$ \\
\hline$P_{\mathrm{A}}^{\max }$ & The maximum asynchronous release rate/vesicle & $0.12 \mathrm{msec}^{-1}$ \\
\hline$K_{\mathrm{p}}$ & The Ca site affinity for the phasic enhancement & 6 (in units of single pulse $\Delta\left[\mathrm{Ca}^{2+}\right]_{i}$ increment) \\
\hline$K_{\mathrm{A}}$ & The Ca site affinity for the asynchronous release & 6 (in units of single pulse $\Delta\left[\mathrm{Ca}^{2+}\right]_{i}$ increment) \\
\hline$N_{p}$ & The cooperativity of the phasic enhancement & 1 \\
\hline$N_{\mathrm{A}}$ & The cooperativity of the asynchronous release & 4 \\
\hline$T_{\mathrm{f} \text { (model) }}$ & The time constant for the fast component of recovery & $250 \mathrm{msec}$ \\
\hline$T_{\mathrm{s} \text { (model) }}$ & The time constant for the slow component of recovery & $20 \mathrm{sec}$ \\
\hline$R_{\mathrm{r}}$ & Size of the RRP at rest & 1 RRP (by definition) \\
\hline$S_{\max }$ & Maximum size of the RP at rest (model a) & 12 RRPs (100 pulse trains), 8 RRPs (20 pulse trains) \\
\hline$K_{\mathrm{f}}$ & The docking rate constant (model a) & $0.31 \mathrm{sec}^{-1}$ (100 pulse trains), $0.44 \mathrm{sec}^{-1}$ (20 pulse trains) \\
\hline$k_{\mathrm{b}}$ & The undocking rate constant (model a) & $3.7 \mathrm{sec}^{-1}$ (100 pulse trains), $3.55 \mathrm{sec}^{-1}$ (20 pulse trains) \\
\hline$q$ & Fraction of fused vesicles that go thorough slow recycling (model b) & 0.083 (100 pulse trains), 0.125 (20 pulse trains) \\
\hline
\end{tabular}

$R_{\mathrm{s}}$ and $R_{\mathrm{f}}$ are the sizes of depleted pools going through slow and fast recycling, respectively, at each moment. $q$ is a constant and is the proportion of fused vesicles that go through slow recycling. By analogy to the classical pool model in Figure $7 A a, q$ is similar to the ratio $R_{r} / S_{\max }$. If we sum both sides of Equation 4 , we can

Table 2. Parameters used for the model 
arrive at the following constraint representing the resting RRP size $\left(R_{\mathrm{r}}\right)$ :

$$
R(t)+R_{s}(t)+R_{f}(t)=R_{r}
$$

An advantage of the alternative model is that we do not need to assume a size and characteristic features of an RP. For example, we do not need to assume a specific docking and undocking rate between pools. As mentioned previously, both models yield similar results and fit to the experimental data (data for model b are not shown). Given that the concept of an RP or store of vesicles is supported by a vast amount of structural and functional literature, we have presented the data using the classical model (RP dependent) but again stress that the slow component of recovery can be described by an alternative model as well. In relation to experimental data, the factor $f$ used to describe the proportion of fast recovery in Figure $4 C$ would be analogous to the proportion $S(t)$ to $S_{\text {max }}$ in model a and the depleted pool $R_{f}(t)$ to $R_{f}(t)+R_{s}(t)$ in model b.

We have fit both models to the 100 pulse train data (Fig. $7 B$ ) and have obtained the following parameters for the model (Table 2 ). Without changing the model (except for the RP size) (Table 2 ), we were able to fit our experimental manipulations such as EGTA-AM and sucrose using the same set of parameters. With regard to the functions that describe the release rate parameters $\left(p_{P}\right.$ and $\left.p_{A}\right)$, we should emphasize that these are not the only models that can describe the observed release rates (Fig. $7 C$ ). We used the stated forms for $p_{P}$ and $p_{A}$ (Eq. 3) that have physiological relevance as fitting tools. The major purpose of the model was not to examine the $\mathrm{Ca}^{2+}$ dependence of phasic and asynchronous release but to study the implications of both modes of release competing for a common pool of quanta.

\section{References}

Abenavoli A, Forti L, Bossi M, Bergamaschi A, Villa A, Malgaroli A (2002) Multimodal quantal release at individual hippocampal synapses: evidence for no lateral inhibition. J Neurosci 22:6336-6346.

Ales E, Tabares L, Poyato JM, Valero V, Lindau M, Alvarez de Toledo G (1999) High calcium concentrations shift the mode of exocytosis to the kiss-and-run mechanism. Nat Cell Biol 1:40-44.

Aravanis AM, Pyle JL, Tsien RW (2003) Single synaptic vesicles fusing transiently and successively without loss of identity. Nature 423:643-647.

Atluri PP, Regehr WG (1996) Determinants of the time course of facilitation at the granule cell to Purkinje cell synapse. J Neurosci 16:5661-5671.

Atluri PP, Regehr WG (1998) Delayed release of neurotransmitter from cerebellar granule cells. J Neurosci 18:8214-8227.

Atwood HL, Karunanithi S (2002) Diversification of synaptic strength: presynaptic elements. Nat Rev Neurosci 3:497-516.

Barrett EF, Stevens CF (1972) The kinetics of transmitter release at the frog neuromuscular junction. J Physiol (Lond) 227:691-708.

Bekkers JM, Stevens CF (1991) Excitatory and inhibitory autaptic currents in isolated hippocampal neurons maintained in cell culture. Proc Natl Acad Sci USA 88:7834-7838.

Bekkers JM, Richerson GB, Stevens CF (1990) Origin of variability in quantal size in cultured hippocampal neurons and hippocampal slices. Proc Natl Acad Sci USA 87:5359-5362.

Berridge MJ, Irvine RF (1989) Inositol phosphates and cell signalling. Nature 341:197-205.

Betz WJ (1970) Depression of transmitter release at the neuromuscular junction of the frog. J Physiol (Lond) 206:629-644.

Birks RI, Maclntosh FC (1961) Acetylcholine metabolism of a sympathetic ganglion. Can J Biochem Physiol 39:787-827.

Blaustein MP, Hodgkin AL (1969) The effect of cyanide on the efflux of calcium from squid axons. J Physiol (Lond) 200:497-527.

Bolshakov VY, Siegelbaum SA (1995) Regulation of hippocampal transmitter release during development and long-term potentiation. Science 269:1730-1734.
Brenowitz S, Trussell LO (2001) Minimizing synaptic depression by control of release probability. J Neurosci 21:1857-1867.

Brody DL, Yue DT (2000) Release-independent short-term synaptic depression in cultured hippocampal neurons. J Neurosci 20:2480-2494.

Chavis P, Westbrook G (2001) Integrins mediate functional pre- and postsynaptic maturation at a hippocampal synapse. Nature 411:317-321.

Cummings DD, Wilcox KS, Dichter MA (1996) Calcium-dependent paired-pulse facilitation of miniature EPSC frequency accompanies depression of EPSCs at hippocampal synapses in culture. J Neurosci 16:5312-5323.

Delaney K, Tank DW, Zucker RS (1991) Presynaptic calcium and serotonin-mediated enhancement of transmitter release at crayfish neuromuscular junction. J Neurosci 11:2631-2643.

Dittman JS, Regehr WG (1998) Calcium dependence and recovery kinetics of presynaptic depression at the climbing fiber to Purkinje cell synapse. J Neurosci 18:6147-6162.

Dixon JF, Hokin LE (1998) Lithium acutely inhibits and chronically upregulates and stabilizes glutamate uptake by presynaptic nerve endings in mouse cerebral cortex. Proc Natl Acad Sci USA 95:8363-8368.

Dobrunz L (2002) Release probability is regulated by the size of the readily releasable vesicle pool at excitatory synapses in hippocampus. Int J Dev Neurosci 20:225-236.

Dobrunz LE, Stevens CF (1997) Heterogeneity of release probability, facilitation, and depletion at central synapses. Neuron 18:995-1008.

Elmqvist D, Quastel DM (1965) A quantitative study of end-plate potentials in isolated human muscle. J Physiol (Lond) 178:505-529.

Forsythe ID, Tsujimoto T, Barnes-Davies M, Cuttle MF, Takahashi T (1998) Inactivation of presynaptic calcium current contributes to synaptic depression at a fast central synapse. Neuron 20:797-807.

Forti L, Bossi M, Bergamaschi A, Villa A, Malgaroli A (1997) Loose-patch recordings of single quanta at individual hippocampal synapses. Nature 388:874-878.

Gadsby DC, Noda M, Shepherd RN, Nakao M (1991) Influence of external monovalent cations on $\mathrm{Na}-\mathrm{Ca}$ exchange current-voltage relationships in cardiac myocytes. Ann NY Acad Sci 639:140-146.

Gandhi SP, Stevens CF (2003) Three modes of synaptic vesicular recycling revealed by single-vesicle imaging. Nature 423:607-613.

Hagler Jr DJ, Goda Y (2001) Properties of synchronous and asynchronous release during pulse train depression in cultured hippocampal neurons. J Neurophysiol 85:2324-2334.

Hanse E, Gustafsson B (2001) Vesicle release probability and pre-primed pool at glutamatergic synapses in area CA1 of the rat neonatal hippocampus. J Physiol (Lond) 531:481-493.

Harata N, Ryan TA, Smith SJ, Buchanan J, Tsien RW (2001) Visualizing recycling synaptic vesicles in hippocampal neurons by FM 1-43 photoconversion. Proc Natl Acad Sci USA 98:12748-12753.

He Y, Zorumski CF, Mennerick S (2002) Contribution of presynaptic $\mathrm{Na}^{+}$ channel inactivation to paired-pulse synaptic depression in cultured hippocampal neurons. J Neurophysiol 87:925-936.

Heinemann C, Chow RH, Neher E, Zucker RS (1994) Kinetics of the secretory response in bovine chromaffin cells following flash photolysis of caged $\mathrm{Ca}^{2+}$. Biophys J 67:2546-2557.

Heuser JE, Reese TS (1973) Evidence for recycling of synaptic vesicle membrane during transmitter release at the frog neuromuscular junction. J Cell Biol 57:315-344.

Honore T, Davies SN, Drejer J, Fletcher EJ, Jacobsen P, Lodge D, Nielsen FE (1988) Quinoxalinediones: potent competitive non-NMDA glutamate receptor antagonists. Science 241:701-703.

Iwasaki S, Takahashi T (2001) Developmental regulation of transmitter release at the calyx of Held in rat auditory brainstem. J Physiol (Lond) 534:861-871.

Katz B, Miledi R (1972) The statistical nature of the acetycholine potential and its molecular components. J Physiol (Lond) 224:665-699.

Li B, Chen N, Luo T, Otsu Y, Murphy TH, Raymond LA (2002) Differential regulation of synaptic and extra-synaptic NMDA receptors. Nat Neurosci 5:833-834.

Liu G, Tsien RW (1995) Synaptic transmission at single visualized hippocampal boutons. Neuropharmacology 34:1407-1421.

Lu T, Trussell LO (2000) Inhibitory transmission mediated by asynchronous transmitter release. Neuron 26:683-694.

Maki R, Cummings DD, Dichter MA (1995) Frequency-dependent depression of excitatory synaptic transmission is independent of activation of 
MCPG-sensitive presynaptic metabotropic glutamate receptors in cultured hippocampal neurons. J Neurophysiol 74:1671-1674.

McKinney RA, Capogna M, Durr R, Gähwiler BH, Thompson SM (1999) Miniature synaptic events maintain dendritic spines via AMPA receptor activation. Nat Neurosci 2:44-49.

Meinrenken CJ, Borst JG, Sakmann B (2003) Local routes revisited: the space and time dependence of the $\mathrm{Ca}^{2+}$ signal for phasic transmitter release at the rat calyx of Held. J Physiol (Lond) 547:665-689.

Millar AG, Bradacs H, Charlton MP, Atwood HL (2002) Inverse relationship between release probability and readily releasable vesicles in depressing and facilitating synapses. J Neurosci 22:9661-9667.

Murphy TH, Baraban JM, Wier WG, Blatter LA (1994) Visualization of quantal synaptic transmission by dendritic calcium imaging. Science 263:529-532.

Murthy VN, Stevens CF (1999) Reversal of synaptic vesicle docking at central synapses. Nat Neurosci 2:503-507.

Murthy VN, Schikorski T, Stevens CF, Zhu Y (2001) Inactivity produces increases in neurotransmitter release and synapse size. Neuron 32:673-682.

Neher E, Sakaba T (2001) Combining deconvolution and noise analysis for the estimation of transmitter release rates at the calyx of held. J Neurosci 21:444-461.

Pyle JL, Kavalali ET, Piedras-Renteria ES, Tsien RW (2000) Rapid reuse of readily releasable pool vesicles at hippocampal synapses. Neuron 28:221-231.

Richards DA, Guatimosim C, Betz WJ (2000) Two endocytic recycling routes selectively fill two vesicle pools in frog motor nerve terminals. Neuron 27:551-559.

Rosenmund C, Stevens CF (1996) Definition of the readily releasable pool of vesicles at hippocampal synapses. Neuron 16:1197-1207.

Ryan TA, Smith SJ (1995) Vesicle pool mobilization during action potential firing at hippocampal synapses. Neuron 14:983-989.

Sakaba T, Neher E (2001) Calmodulin mediates rapid recruitment of fastreleasing synaptic vesicles at a calyx-type synapse. Neuron 32:1119-1131.

Sankaranarayanan S, Ryan TA (2001) Calcium accelerates endocytosis of vSNAREs at hippocampal synapses. Nat Neurosci 4:129-136.

Sara Y, Mozhayeva MG, Liu X, Kavalali ET (2002) Fast vesicle recycling supports neurotransmission during sustained stimulation at hippocampal synapses. J Neurosci 22:1608-1617.

Scanziani M, Salin PA, Vogt KE, Malenka RC, Nicoll RA (1997) Usedependent increases in glutamate concentration activate presynaptic metabotropic glutamate receptors. Nature 385:630-634.

Scheuss V, Schneggenburger R, Neher E (2002) Separation of presynaptic and postsynaptic contributions to depression by covariance analysis of successive EPSCs at the calyx of held synapse. J Neurosci 22:728-739.
Schikorski T, Stevens CF (1999) Quantitative fine-structural analysis of olfactory cortical synapses. Proc Natl Acad Sci USA 96:4107-4112.

Schneggenburger R, Meyer AC, Neher E (1999) Released fraction and total size of a pool of immediately available transmitter quanta at a calyx synapse. Neuron 23:399-409.

Stevens CF, Tsujimoto T (1995) Estimates for the pool size of releasable quanta at a single central synapse and for the time required to refill the pool. Proc Natl Acad Sci USA 92:846-849.

Stevens CF, Wesseling JF (1998) Activity-dependent modulation of the rate at which synaptic vesicles become available to undergo exocytosis. Neuron 21:415-424.

Stevens CF, Wesseling JF (1999a) Augmentation is a potentiation of the exocytotic process. Neuron 22:139-146.

Stevens CF, Wesseling JF (1999b) Identification of a novel process limiting the rate of synaptic vesicle cycling at hippocampal synapses. Neuron 24:1017-1028.

Südhof TC (2000) The synaptic vesicle cycle revisited. Neuron 28:317-320.

Sun JY, Wu XS, Wu LG (2002) Single and multiple vesicle fusion induce different rates of endocytosis at a central synapse. Nature 417:555-559.

Takahashi T, Forsythe ID, Tsujimoto T, Barnes-Davies M, Onodera K (1996) Presynaptic calcium current modulation by a metabotropic glutamate receptor. Science 274:594-597.

Thomson AM (2000) Molecular frequency filters at central synapses. Prog Neurobiol 62:159-196.

von Gersdorff H, Matthews G (1994) Inhibition of endocytosis by elevated internal calcium in a synaptic terminal. Nature 370:652-655.

von Gersdorff H, Matthews G (1997) Depletion and replenishment of vesicle pools at a ribbon-type synaptic terminal. J Neurosci 17:1919-1927.

Wang LY, Kaczmarek LK (1998) High-frequency firing helps replenish the readily releasable pool of synaptic vesicles. Nature 394:384-388.

Wesseling JF, Lo DC (2002) Limit on the role of activity in controlling the release-ready supply of synaptic vesicles. J Neurosci 22:9708-9720.

Wu LG, Betz WJ (1998) Kinetics of synaptic depression and vesicle recycling after tetanic stimulation of frog motor nerve terminals. Biophys J 74:3003-3009.

Wu LG, Borst JG (1999) The reduced release probability of releasable vesicles during recovery from short-term synaptic depression. Neuron 23:821-832.

Xu-Friedman MA, Harris KM, Regehr WG (2001) Three-dimensional comparison of ultrastructural characteristics at depressing and facilitating synapses onto cerebellar Purkinje cells. J Neurosci 21:6666-6672.

Zucker RS, Regehr WG (2002) Short-term synaptic plasticity. Annu Rev Physiol 64:355-405. 